\title{
Barotropic Energy Conversion During Indian Summer Monsoon: Implication of Central Indian Ocean Mode Simulation in CMIP6
}

Jianhuang Qin

Hohai University

Lei Zhou ( $\square$ zhoulei1588@sjtu.edu.cn )

Shanghai Jiao Tong University https://orcid.org/0000-0002-0433-3991

\section{Ze Meng}

Shanghai Jiao Tong University

\section{Baosheng Li}

State Key Laboratory of Satellite Ocean Environment Dynamics

Tao Lian

State Key Laboratory of Satellite Ocean Environment Dynamics

\section{Raghu Murtugudde}

University of Maryland at College Park

\section{Research Article}

Keywords: central Indian Ocean (CIO), Dynamic diagnostics, CMIP6, MISO

Posted Date: July 27th, 2021

DOI: https://doi.org/10.21203/rs.3.rs-715759/v1

License: (c) (1) This work is licensed under a Creative Commons Attribution 4.0 International License.

Read Full License

Version of Record: A version of this preprint was published at Climate Dynamics on January 11th, 2022. See the published version at https://doi.org/10.1007/s00382-021-06087-y. 


\section{Implication of Central Indian Ocean Mode Simulation in CMIP6}

4 Jianhuang Qin ${ }^{1,2}$, Lei Zhou ${ }^{3,4 *}$, Ze Meng ${ }^{3}$, Baosheng $\operatorname{Li}^{2}$, Tao Lian ${ }^{2,3,4}$,

6 1. College of Oceanography, Hohai University, Nanjing, China

$7 \quad$ 2. State Key Laboratory of Satellite Ocean Environment Dynamics, Second Institute of 8 Oceanography, Ministry of Natural Resources, Hangzhou, China

9 3. School of Oceanography, Shanghai Jiao Tong University, Shanghai, China

10 4. Southern Marine Science and Engineering Guangdong Laboratory (Zhuhai)

11 5. University of Maryland, College Park, Maryland, USA 

Abstract

The simulation and prediction of the Indian summer monsoon (ISM) and its

intraseasonal component in climate models remain a grand scientific challenge for models. Recently, an intraseasonal mode was proposed over the tropical Indian Ocean, named central Indian Ocean (CIO) mode. The CIO mode index and with monsoon intraseasonal oscillations (MISO) have a high correlation. In this study, the simulations of the CIO mode in the sixth phase of the Coupled Model Intercomparison Project (CMIP6) models are examined. Although the coupled ocean-atmosphere feedbacks associated with the CIO mode are not fully reproduced, the results show that a better depiction of the CIO mode in CMIP6 models is favorable for a better simulation of northward-propagating MISO and heavy rainfall during the ISM. Dynamic diagnostics unveil that the rendition of the CIO mode is dominated by kinetic energy conversion from the background to the intraseasonal variability. Furthermore, kinetic energy conversion is controlled by the meridional shear of background zonal winds $\left(\frac{\partial \bar{u}}{\partial y}\right)$, which is underestimated in most CMIP6 models, leading to a weak barotropic instability. As a result, a better simulation of $\frac{\partial \bar{u}}{\partial y}$ is required for improving the CIO mode simulation in climate models, which helps to improve the simulation and prediction skill of northward-propagating MISO and monsoonal precipitation. 


\section{Introduction}

The Indian summer monsoon (ISM) precipitation has tremendous scientific and socioeconomic significance, which contributes about $80 \%$ of the total annual precipitation over the Indian subcontinent (Bollasina, 2014) and has a substantial influence on agricultural and industrial productions. The ISM precipitation has two significant timescales; one is between 30 and 60 days [known as intraseasonal variability; Yasunari, 1981], and the other one is between 10 and 20 days (i.e., quasibiweekly variability; Chatterjee and Goswami, 2004). The former is controlled by the monsoon intraseasonal oscillation (MISO; Goswami 2005; Shukla 2014), which dominates the active and break spells in monsoonal precipitation. MISO can explain approximately $60 \%$ of total precipitation variance over the Bay of Bengal (BoB) (Goswami 2005; Waliser 2006; Shukla 2014). To date, the simulation and prediction of monsoonal precipitation and MISO remains a great challenge for contemporary models (e.g., Sabeerali et al. 2013; Wang et al. 2015; Goswami and Chakravorty, 2017; Hazra et al. 2017). The predictability of ISM is dependent on its close relationship with the El Niño-Southern Oscillation (ENSO, e.g., Gill et al. 2015), the Atlantic Niño (Pottapinjara et al. 2014) and the Indian Ocean Dipole/Zonal Mode (IODZM, e.g., Murtugudde et al. 2000; Ashok et al. 2001). However, the intraseasonal variabilities are considered as a "desert of predictability" for a long time (Waliser et al. 2003; Vitart et al. 2017). Thus, insight into intraseasonal variabilities over the tropical Indian Ocean can help to facilitate a better simulation of the ISM, and to advance predictive understanding of the ISM precipitation. 
Recently, an intraseasonal mode, i.e., the central Indian Ocean (CIO) mode, was proposed by Zhou et al. (2017a). It is proved that the CIO mode is closely related to MISO propagation and monsoonal precipitation. The CIO mode is obtained by the first combined Empirical Orthogonal Function (EOF) mode of intraseasonal sea surface temperatures (SSTs) and intraseasonal $850 \mathrm{hPa}$ zonal winds (referred to as U850 hereafter) over the tropical Indian Ocean, and the corresponding principal component (PC) is referred to as the $\mathrm{CIO}$ mode index. The $\mathrm{CIO}$ mode is not sensitive to the reanalysis products and spatiotemporal domains (Zhou et al. 2017a, 2018; Qin et al. 2020). The spatial pattern of the positive CIO mode is shown in Fig. 1a during the period of 1998-2014. The intraseasonal SST node of the positive CIO mode captures positive anomalies along the central Indian Ocean, accompanied with an anti-cyclonic gyre in the lower troposphere. The CIO mode is energetic during boreal summer (JuneSeptember), which is attributable to the enhanced transmission of kinetic energy from the background state to the intraseasonal timescales (Zhou et al. 2017b). It is verified that the positive CIO mode plays an important role in driving the heavy precipitation during the ISM, via changing the propagation direction of the intraseasonal oscillations (Zhou et al. 2017a; Qin et al. 2020). The positive CIO mode facilitates the transition from the eastward-propagating intraseasonal variabilities [commonly known as Madden-Julian oscillation (MJO); Madden and Julian 1971, 1972; Zhang 2005] to the northward-propagating component during the ISM, since the easterly vertical wind shear associated with the positive CIO mode are favorable for the latter (Fu et al. 2004; Jiang et al. 2004; Kang et al. 2010; Zhou and Murtugudde 2014). As a result, the 
positive CIO mode shows a significant positive correlation with intraseasonal precipitation over the $\mathrm{BoB}$ (Fig. 1b), where the total rainfall and intraseasonal rainfall variance are large (Fig. 1c and d). It is also argued that the relationships of the CIO mode with MISO and ISM are independent on ENSO and IODZM (Zhou et al. 2017b), which indicates that the $\mathrm{CIO}$ mode can provide an independent way to improve the simulation of MISO and monsoonal precipitation.

The evaluation of CIO mode simulations was investigated in the Community Earth System Model (CESM) and Subseasonal-to-Seasonal (S2S) air-sea coupled models (Zhou et al. 2018; Qin et al. 2020). A consistent conclusion was that a better depiction of the CIO mode in a model tends to a better reappearance of northward-propagating MISO and heavier intraseasonal rainfall during the ISM. However, the CIO mode is not well captured in CESM. As a result, the simulated monsoonal precipitation and the northward-propagating MISO are weaker than observed. Although most of the S2S airsea coupled models can reproduce the CIO mode on initial days, the simulations of the CIO mode become deficient rapidly as the lead time for forecast increases. Such biases in the CIO mode simulation are mainly attributed to the weak meridional shear of the low-frequency zonal winds (a low-pass filter of 100 days) in the above climate models, which reduces the barotropic kinetic energy conversion from the background state to intraseasonal variabilities. Hence, the $\mathrm{CIO}$ mode is not strong enough to reinforce the moisture loading in the subtropical mid-level troposphere, which benefits the northward propagation of MISO. In addition, the intraseasonal meridional wind related to the CIO mode is also important for the moisture transport over the BoB in S2S air-sea coupled 
models.

Nevertheless, the evaluations of the CIO mode simulation were only based on CESM and 6 air-sea coupled models in the S2S database. More state-of-the-art climate models are needed to examine the simulation of the CIO mode as well as its impacts on the simulation of MISO and the ISM. The Coupled Model Intercomparison Project (CMIP), which began in 1995 under the auspices of the World Climate Research Programme (WCRP), is now in its sixth phase (CMIP6). Some studies have suggested that the CMIP6 models yield better simulations of MJOs than the CMIP5 models, such as a slower eastward propagation, stronger teleconnection pattern, and longer persistence of MJOs (e.g., Ahn et al. 2020; Wang et al. 2020). The intercomparisons among different CMIP6 models help to promote the process understandings of the CIO mode and are expected to improve the simulations of MISO and monsoonal precipitation. This is the motivation for this paper. The remainder of this paper is organized as follows. Section 2 introduces model configurations and the methods used in this study. In Section 3, the assessments of the CIO mode and related processes simulations are examined. Finally, the summary and discussion are shown in Section 4.

\section{Data and methods}

The simulated daily atmospheric and oceanic data (including SST, winds, precipitation and specific humidity) are retrieved from the Earth System Grid (ESG) data portal for 18 CMIP6 models (https://esgf-node.llnl.gov/search/cmip6/), which are 
from the Historical experiments during the period of 1998-2014 (the time range for the study). The Historical experiments represent present-day climate, and only the first ensemble member (r1ilp1f1) is analyzed from each CMIP6 model. The general information of the 18 CMIP6 models, including model resolutions and model numbers, are listed in Table 1. Before the inter-comparison among different models, all variables are interpolated to a horizontal resolution of $0.5^{\circ}$ latitude $\times 0.5^{\circ}$ longitude, which has no impacts on the extraction of intraseasonal variabilities in this study (not shown).

Daily SST data with a resolution of $0.25^{\circ}$ latitude $\times 0.25^{\circ}$ longitude from 1998 to 2014 are obtained from the National Oceanic and Atmospheric Administration (NOAA) Optimum Interpolated SST (OISST; Reynolds et al. 2007). Atmospheric variables are obtained from the European Center for Medium-Range Weather Forecast (ECMWF) ERA5 reanalysis dataset (Hersbach et al. 2019), including winds and specific humidity, with horizontal resolution of $0.25^{\circ} \times 0.25^{\circ}$ and temporal resolution of 6 hours during the period of 1998-2014. Daily precipitation during the same period is the 3B42 product from the Tropical Rainfall Measuring Mission (TRMM) rainfall data (Kummerow et al. 2000). All intraseasonal oscillations in both simulations and observations are obtained with a 20-100-day band-pass Butterworth filter. Student's $t$-test on the basis of a difference between sample means is used to test the statistical significance of the correlation coefficient.

The projection method is adopted to acquire the CIO mode index in CMIP6 models. The projected CIO mode index is calculated as

$$
A(x, y, t)=B(x, y) \cdot \text { index }(t)+R 1 \ldots
$$


where $\mathrm{A}$ is the three-dimensional data including intraseasonal SST and U850 anomalies; B represents the spatial structure of the observed CIO mode; R1 is the residual term; $\mathrm{x}, \mathrm{y}$ and $\mathrm{t}$ are the number of latitude, longitude and time, respectively.

\section{Results}

\subsection{Simulation of the Mean Climate State and the Monsoon}

Figure 2 shows the difference of mean SST between observations and simulations in CMIP6 models (simulations minus observations) during boreal summer (JuneSeptember). The differences are less than $2{ }^{\circ} \mathrm{C}$ in the tropical Indian Ocean. The Indian Ocean warm pool exists along the equator from the central to the eastern Indian Ocean (contours in every panel in Fig. 2), but they are underestimated in CMIP6 models. Conversely, the simulated SSTs in the western Indian Ocean are warmer than the observations. The exceptions are MPI-ESM-1-2-HAM, MPI-ESM1-2-LR and NESM3 (\#11, 13 and 15, Fig 2k, $\mathrm{m}$ and o), in which the mean simulated SSTs are colder than the observations over the entire tropical Indian Ocean during boreal summer. The differences of the simulated mean U850 from the observations are shown in Fig. 3. The U850 in reanalysis consist westerlies (easterlies) in the north (south) of equator over the tropical Indian Ocean during boreal summer (contours). Although the bias of U850 is less than $5 \mathrm{~m} \mathrm{~s}^{-1}$, almost all models represent stronger westerlies over the BoB (except IPSL-CM6A-LR, \#9, Fig. 3i) and weaker westerlies over the Arabian sea. The weak westerly biases reduce upwelling in the western basin, probably leading to the warm SST bias in models (Fig. 2). Moreover, the easterlies along the equator are weaker than 
those in observations, leading to reduced warm water convergence to the warm pool. As a result, the SSTs on the equator are colder in CMIP6 models.

The mean precipitation in observations reach the maximum over the BoB (Fig. 1c) during boreal summer (from June to September). The standard deviation (STD) of intraseasonal rainfall is also large at the same locations (Fig. 1d). As shown in Fig.4, the mean precipitation and the STD of intraseasonal precipitation averaged within $10^{\circ}$ $20^{\circ} \mathrm{N}$ and $80^{\circ}-100^{\circ} \mathrm{E}$ during boreal summer are $13.77 \mathrm{~mm} \mathrm{day}^{-1}$ (red line) and $9.4 \mathrm{~mm}$ day $^{-1}$ (gray line) in TRMM, respectively. Similarly, the red and gray bars in Fig. 4 represent the mean precipitation and the STD of intraseasonal precipitation calculated using CMIP6 models, respectively. One can see that the precipitation and its intraseasonal variability are much weaker in all CMIP6 models than in nature. It indicates that the underestimated monsoonal precipitation remains a persistent problem for most climate models. Due to the close relationship between the CIO mode and ISM, it can be reasonably assumed that the simulated CIO mode is not strong enough in CMIP6 models. Therefore, there are likely to be some inadequacies in the simulation of CIO mode and its processes, which are discussed in more detail below.

\subsection{Evaluation of Simulated CIO Mode}

The CIO mode is defined as the first combined EOF mode between intraseasonal SST anomalies and intraseasonal U850 anomalies. Figure 5 shows the simulated CIO mode calculated by CMIP6 model outputs. The variance explanations of the simulated CIO mode range from $7.0 \%$ to $10.4 \%$ in CMIP6 models (around $9.2 \%$ in ERA5 
reanalysis, Fig. 1a). In nature, the anti-cyclone and corresponding downdraft enhance the easterly vertical wind shear, which benefits the northward propagation of MISO (Zhou et al. 2017a). Meanwhile, the downdraft over the central Indian Ocean increases the incident solar radiation at the sea surface, leading to warm SST anomalies during the positive CIO mode. It suggests that the atmosphere plays an active role in the oceanatmosphere interaction (Xi et al. 2015). In the simulations, the easterlies along the equator associated with the positive phase of CIO mode are well captured in almost all CMIP6 models (contours in Fig. 5), except ACCESS-ESM1-5 and GFDL-CM4 (\#2, 8, Fig. $5 \mathrm{~b}$ and $5 \mathrm{~h}$ ), which are dominated by westerlies along the equator. However, westerly wind anomalies, which in reality are around $10^{\circ} \mathrm{N}$, are barely evident in either simulation. Compared with observations and the ERA5 reanalysis (Fig. 1a), the simulated westerly wind anomalies shift to the southern hemisphere in CMIP6 models. As a result, the warm SST anomalies in the central Indian Ocean are quite realistic in CMIP6 models (colors in Fig. 5). The mismatch between the simulations and observations reveals the inadequacy of the ocean-atmosphere coupling, which is a typical shortcoming of monsoon simulations as emphasized by many previous studies (e.g., Meehl et al. 2012; Goswami et al. 2014).

Given the misrepresentation of SSTs in the simulated CIO mode using the EOF analysis, another way to evaluate the simulated CIO mode is to project the model outputs onto the observed CIO mode (Fig. 1a). The purpose of the projection method is to estimate how much actual CIO mode is captured in each CMIP6 model simulation. The projected CIO mode index in CMIP6 models is calculated by Eq. (1). Figure 6 
shows the correlation coefficients of intraseasonal precipitation with the projected CIO mode index during boreal summer (from June to September) in each CMIP6 model. It is obvious that the correlations over the $\mathrm{BoB}$ are significantly positive with a maximum over 0.5 in all CMIP6 models, which emphasizes the close relationship between the CIO mode and monsoonal precipitation.

The STDs of projected CIO mode index during the ISM (from June to September) are shown in the x-axis of Fig. 7, which represents the intensity of the simulated CIO mode in each CMIP6 model. The $\mathrm{y}^{-}$axis in Fig. 7 represents the strength of intraseasonal precipitation over the $\mathrm{BoB}\left(10^{\circ}-20^{\circ} \mathrm{N}, 80^{\circ}-100^{\circ} \mathrm{E}\right.$, the same as gray bars in Fig. 5). The correlation coefficient between the STD of intraseasonal precipitation and the STD of projected CIO mode index is 0.71 (significant at a $99 \%$ confidence level). This result also indicates that a pronounced CIO mode is helpful to enhance the monsoonal precipitation, which is lacking in most CMIP6 models. Particularly, CESM2-FV2, CESM2-WACCM-FV2, MIROC6 and SAM0-UNICON (\#5, 6, 10 and 18, considered as the well simulated group, listed in Tab. 2) show better simulations of monsoonal precipitation and the CIO mode than the other models do, and all of them reproduce higher mean precipitation and stronger intraseasonal precipitation (red and gray bars in Fig. 5). Moreover, the correlations of intraseasonal precipitation with the projected CIO mode index in the well simulated group are also higher than other models (Fig. 6d, e, j and r), and more similar to that in observations (Fig. 1b). In contrast, the STDs of the CIO mode are weak in ACCESS-CM2, ACCESS-ESM1-5, CanESM5 and IPSL-CM6A-LR (\#1, 2, 3 and 9, considered as the poorly simulated group, listed in 
Tab. 2). This leads to weak STD of monsoonal precipitation and lower correlations with intraseasonal precipitation over the BoB (Fig. 6a, b, c, and i) during the ISM.

Furthermore, the energetics of MISO are examined from the equator to $30^{\circ} \mathrm{N}$ during the positive CIO mode events (Zhou et al. 2017a; Qin et al. 2020). According to the CIO mode index, the positive CIO mode events are defined by a local maximum and larger than its STD during boreal summer (June-September). There are 54 positive CIO mode events using ERA5 reanalysis and OISST from 1998 to 2014. The numbers of positive CIO mode events using the projected CIO mode index in each CMIP6 model are listed in Tab. 3. Almost all CMIP6 models represent slightly more positive CIO mode events (ranges from 52 to 68 ) than observations. The northward MISO propagation can be clearly seen in the Hovmöller diagrams of intraseasonal zonal winds (colors), intraseasonal outgoing longwave radiation (OLR; white contours), and intraseasonal rainfall (black contours) averaged between $80^{\circ} \mathrm{E}$ and $90^{\circ} \mathrm{E}$ in most $\mathrm{CMIP} 6$ models (along the green reference lines, Fig. 8). Day 0 on the $\mathrm{x}$-axis is the day when the projected CIO mode index peaks during the ISM. In comparison, the speed of northward propagation has no obvious difference (approximate $1^{\circ}$ day $^{-1}$ ) among different models. The maximum of intraseasonal precipitation is higher than $5 \mathrm{~mm}$ day${ }^{1}$ with negative OLR anomalies below $15 \mathrm{~W} \mathrm{~m}^{-2}$ and can reach up to $30^{\circ} \mathrm{N}$ in the well simulated group (\#5, 6, 10, and 18; Fig. 8e, f, j and r) when the projected CIO mode index peaks. However, the intraseasonal zonal winds, precipitation and OLR are much weaker in the poorly simulated group (\#1, 2, 3 and 9; Fig. 8a, b, c and i), and are restricted to the south of $20^{\circ} \mathrm{N}$. Therefore, it can be concluded that a better simulation 
of the CIO mode benefits the simulations of northward-propagating MISO and

259 monsoonal precipitation during the ISM.

\subsection{Dynamics of the CIO mode in CMIP6 models}

Figure 9 shows the composite of simulated intraseasonal specific humidity and vertical velocity averaged between $80^{\circ} \mathrm{E}$ and $90^{\circ} \mathrm{E}$ on the peak days of the $\mathrm{CIO}$ mode index. The intraseasonal specific humidity (colors) shows negative anomalies over the equator and positive anomalies to the north of $20^{\circ} \mathrm{N}$ and upward to the mid-troposphere in all CMIP6 models. These conditions together with the vertical velocity (contours) play an important role in generating precipitation. Positive specific humidity anomalies and upward motions induce the heavy rainfall and latent heat release between $10^{\circ} \mathrm{N}$ and $25^{\circ} \mathrm{N}$. However, the upward motions are not well captured in all CMIP6 models (dashed contours in Fig. 9). The center of upward motions hardly reaches the north of $20^{\circ} \mathrm{N}$ in most CMIP6 models. Particularly, they are weak in the poorly simulated group (\#1, 2, to each other in a coupled system. 

budget is checked for the CMIP6 models. All variables are decomposed into three components. For instance, the zonal wind is decomposed as $u=\bar{u}+u^{\prime}+u^{\prime \prime}$, where $\bar{u}$ is obtained with a low-pass filter of 100 days representing the background state of zonal wind, $u^{\prime}$ is the intraseasonal zonal wind, and $u^{\prime \prime}$ (obtained with a high-pass filtering of 20 days) is the high-frequency variability. Following Zhou et al. (2012), the budget of intraseasonal kinetic energy $\left(K E^{\prime}\right)$ is written as

$$
\begin{aligned}
\frac{\partial K E^{\prime}}{\partial t}=-\overline{\boldsymbol{V}} \cdot \nabla K E^{\prime}+\left[K E^{\prime} \times \overline{K E}\right]+\left[K E^{\prime} \times K E^{\prime \prime}\right]+\left[K E^{\prime} \times P E^{\prime}\right]-\nabla\left(\boldsymbol{V}^{\prime} \cdot \Phi^{\prime}\right) \\
+R 2 \cdots(2)
\end{aligned}
$$

where $\boldsymbol{V}, \Phi$ and PE represent the horizontal wind (including zonal and meridional winds), geopotential and potential energy, respectively; $-\overline{\boldsymbol{V}} \cdot \nabla K E^{\prime}$ is the advection term of intraseasonal kinetic energy; $\left[K E^{\prime} \times \overline{K E}\right]$ represents the kinetic energy conversion between the background and intraseasonal variabilities; $\left[K E^{\prime} \times K E^{\prime \prime}\right]$ is the conversion between the intraseasonal kinetic energy variabilities and higher 294 frequency oscillations; $\left[K E^{\prime} \times P E^{\prime}\right]$ represents the energy conversion between intraseasonal kinetic energy and potential energy; $-\nabla\left(\overline{\boldsymbol{V}}^{\prime} \cdot \Phi^{\prime}\right)$ is the work done by the pressure gradient force; and R2 is the residual term. More details of the kinetic energy budget can be seen in Zhou et al. (2012). regions, i.e., the Indian Peninsula to BoB, Arabian Sea, and the central Indian Ocean around the equator (Fig. 10a). The former two are related to the ISM, and the last one is associated with the CIO mode. These results are consistent with that calculated by 
ERA-Interim data and NCEP Reanalysis 2 (Zhou et al. 2017b; Zhou et al. 2018).

According to the kinetic energy budget analysis (Eq. 2), the kinetic energy on intraseasonal timescales is provided by $\left[K E^{\prime} \times \overline{K E}\right]$ during the ISM, while other terms in Eq. (2) are generally small. As shown in Fig. 10b, positive $\left[K E^{\prime} \times \overline{K E}\right]$ represents kinetic energy conversion from the background to the intraseasonal variabilities, which boosts the kinetic energy on intraseasonal timescales. In the simulations, the intraseasonal kinetic energy and $\left[K E^{\prime} \times \overline{K E}\right]$ at $850 \mathrm{hPa}$ averaged during the ISM in CMIP6 models are shown in Fig. 11 and Fig. 12, respectively. A noticeable bias is that the pronounced intraseasonal kinetic energy over the central Indian Ocean is largely missing in all CMIP6 models, due to the weaker $\left[K E^{\prime} \times \overline{K E}\right]$ along the equator. However, the intraseasonal kinetic energy center associated with strong $\left[K E^{\prime} \times \overline{K E}\right]$ over the BoB is well captured in most CMIP6 models, especially in the well simulated group (\#5, 6, 10 and 18; Fig. 11e, f, j and r). In contrast, the intraseasonal kinetic energy over the BoB is smaller than $5 \mathrm{~J} \mathrm{~kg}^{-1}$ in the poorly simulated group (\#1, 2, 3 and 9; Fig. 11a, b, c and i), in which the simulations of the ISM are weak. Moreover, $\left[K E^{\prime} \times \overline{K E}\right]$ is also weak ( smaller than $2 \mathrm{~J} \mathrm{day}^{-1} \mathrm{~kg}^{-1}$ ) in the poorly simulated group (\#1, 2, 3 and 9; Fig. 12a, b, c and i). As a result, the intraseasonal kinetic energy is not strong enough for capturing the $\mathrm{CIO}$ mode and the monsoonal precipitation.

Previous studies have demonstrated that the kinetic energy transfer from the background to the intraseasonal variability is dominated by the barotropic instability of the background state (Holton and Hakim 2013; Vallis 2017). $\left[K E^{\prime} \times \overline{K E}\right]$ is driven by the meridional shear of background zonal winds $\left(\frac{\partial \bar{u}}{\partial y}\right)$ during the ISM. In the reanalysis 
324 (Fig. 10c), $\frac{\partial \bar{u}}{\partial y}$ shows a meridional train of positive and negative values from the equator up to $30^{\circ} \mathrm{N}$ (particularly between $70^{\circ} \mathrm{E}$ and $100^{\circ} \mathrm{E}$ ). Consistently, the changes

326 in signs can be seen in the meridional gradient of the quasi-geostrophic potential 327 vorticity $\left(\mathrm{PV}, \frac{d P V}{d y}=\beta-\frac{\partial^{2} \bar{u}}{\partial y^{2}}\right.$, where $\beta$ is the meridional gradient of the Coriolis 328 parameter) from the equator to the north. As shown in Fig. 10d, positive and negative 329 values of $\beta-\frac{\partial^{2} \bar{u}}{\partial y^{2}}$ occur alternatively in the meridional direction within the ISM 330 region, which is indicative of the necessary condition for the barotropic instability 331 (Vallis 2017). Conversely, $\frac{\partial \bar{u}}{\partial y}$ is too weak in CMIP6 models (Fig. 13). $\frac{\partial \bar{u}}{\partial y}$ reaches a 332 positive maximum around the equator and decreases almost monotonically to its 333 minimum around $20^{\circ} \mathrm{N}$. As a result, $\frac{\partial^{2} \bar{u}}{\partial y^{2}}$ in CMIP6 has the same sign in this region and 334 it is not strong enough to overcome $\beta$ (Fig. 14). Therefore, the necessary condition for 335 the barotropic instability over the BoB cannot be satisfied in CMIP6 models. Compared 336 with the assessment of intraseasonal kinetic energy in CESM and S2S models (zhou et al. 2018; Qin et al. 2020), it can be surmised that the underestimated barotropic 338 instability in contemporary climate models is the essential reason for poor simulation of the CIO mode and monsoonal precipitation.

\section{Summary and Discussion}

The CIO mode has a strong association with the northward propagation of MISO and monsoonal precipitation during the ISM, via transferring energy and moisture from the tropics to the subtropical regions. However, previous studies have investigated that the simulation of CIO mode in current climate models is poor (Zhou et al. 2018; Qin et 
al. 2020). In this study, we examined the evaluations of the CIO mode simulation in CMIP6 models. The simulated monsoonal rainfall and its variability on intraseasonal timescale are much weaker than observations. Although the mismatch of the coupled relation between the ocean and the atmosphere associated with the CIO mode remains in CMIP6 models, results confirm that a pronounced CIO mode is helpful to reinforce the northward propagation of MISO and to enhance the monsoonal precipitation over the BoB. Probing deeper, the intraseasonal kinetic energy budget analysis revealed that the poor simulations of the $\mathrm{CIO}$ mode and its processes are attributable to the misrepresentation of background winds. Weak meridional shear of background zonal winds $\left(\frac{\partial \bar{u}}{\partial y}\right)$ in CMIP6 models reduces the kinetic energy conversion from the background state to the intraseasonal variabilities. Then, the intraseasonal kinetic energy is not strong enough to raise a CIO mode event in CMIP6 models. Therefore, barotropic instability is underestimated from the equator up to $30^{\circ} \mathrm{N}$ (particularly between $70^{\circ} \mathrm{E}$ and $100^{\circ} \mathrm{E}$ ), and is found to be very weak in most current climate models. Our conclusion that better CIO simulation in CMIP6 models is mainly due to the intensity of the barotropic instability is also supported by the recent model intercomparison studies conducted by Zhou et al. (2018) and Qin et al. (2020). They also found that the couple SST - wind relation between the ocean and the atmosphere in those simulations are opposite to that in observations. Such a mismatch of the ocean and the atmosphere is reduced in CMIP6 models. The bias of SSTs in CMIP6 models is attributed to the poor simulation of winds. Although higher resolution in models show improvements, enhancing the model physics suitable for the higher resolution is also 
essential. Therefore, more attention is needed for improving both dynamic circulation and thermodynamic processes in climate models, which is expected to in turn improve the simulations of MISO and ISM. central Indian Ocean is favorable for driving intraseasonal oscillations (Zhou et al. 2017a; Li et al. 2020). The easterly wind shear during boreal summer is found to be well captured in CMIP6 models (Li et al. 2021). Therefore, the intensity of northward reported elsewhere. boreal summer season focus on the CIO mode. Since the barotropic instability condition during boreal summer is not satisfied in current climate models, numerical experiments may provide us with a better way to understand the importance of barotropic instability for the $\mathrm{CIO}$ mode generation and the air-sea interactions related to the $\mathrm{CIO}$ mode. Further improvements in convection parameterization schemes associated with barotropic instability in models will be helpful for the betterment of MISO and will lead to the improved simulation of monsoon. This is our future goal and the results will be 
This work is supported by grants from the National Natural Science Foundation

389 of China (42076001), the open fund of State Key Laboratory of Satellite Ocean

390 Environment Dynamics, Second Institute of Oceanography, MNR (No. QNHX2111),

391 and the Fundamental Research Funds for the Central Universities (B210202142). RM

392 gratefully acknowledges the Visiting Faculty at the Indian Institute of Technology,

393 Bombay. All observation data and reanalysis products for this paper are properly cited

394 and referred to in the reference list. TRMM 3B42 product observation data are

395 downloaded from https://gpm.nasa.gov/data-access/downloads/trmm. OISST

396 reanalysis are obtained from $\underline{\mathrm{https}}$ //www.ncdc.noaa.gov/oisst. ERA5 reanalysis are

397 available at https://www.ecmwf.int/en/forecasts/datasets/reanalysis-datasets/era5. 


\section{Reference}

Ahn MS et al (2020) MJO propagation across the Maritime Continent: Are CMIP6 models better than CMIP5 models? Geophys Res Lett 47:e2020GL087250. https://doi.org/ 10.1029/2020GL087250

Ashok K, Guan Z, Yamagata T (2001) Impact of the Indian Ocean Dipole on the relationship between the Indian monsoon rainfall and ENSO. Geophys Res Lett 28(23):4499-4502. https://doi.org/10.1029/2001GL013294

Bollasina MA (2014) Hydrology: probing the monsoon pulse. Nat Clim Change 4:422. https://doi.org/10.1038/nclimate2243

Chatterjee P, Goswami BN (2004) Structure, genesis and scale selection of the tropical quasi-biweekly mode. Quart J R Meteor Soc 130:1171-1194. https://doi.org/10.1256/qj.03.133

Fu X, Wang B, Li T, McCreary JP (2004) Differences of boreal summer intraseasonal oscillations simulated in an atmosphereocean coupled model and an atmosphereonly model. J Clim 17:1263-1271. https://doi.org/10.1175/15200442(2004)017<1263:DOBSIO >2.0.CO;2

Gill EC, Rajagopalan B, Molnar P (2015) Subseasonal variations in spatial signatures of ENSO on the Indian summer monsoon from 1901 to 2009. J Geophys Res Atmos 120:8165-8185. doi:10.1002/2015JD023184

Goswami BN (2005) South Asian monsoon. In Intraseasonal variability in the atmosphere-ocean climate system (pp. 19-61). Springer, Berlin, Heidelberg. https://xs.scihub.ltd/https://doi.org/10.1007/3-540-27250-X_2

Goswami BB, Deshpande M, Mukhopadhyay P, Saha SK, Rao SA, Murthugudde R, Goswami BN (2014) Simulation of Indian summer monsoon intraseasonal oscillation variability in NCEP CFSv2 and its role on systematic bias. Clim Dyn 43:2725-2745. doi:10.1007/s00382-014-2089-5

Hazra A, Chaudhari HS, Saha SK, Pokhrel S (2017) Effect of cloud microphysics on Indian summer monsoon precipitating clouds: a coupled climate modeling study. J Geophys Res Atmos 122:3786-3805. https://doi.org/10.1002/2016JD026106 
Hersbach H, Bell B, Berrisford P et al (2019) Global reanalysis: goodbye ERA-Inteirm, hello ERA5. ECMWF Newsl 159:17-24. https://doi.org/10.21957/vf291hehd7

Holton JR, Hakim GJ (2013) An introduction to dynamic meteorology. Waltham, MA. https://doi.org/10.1016/C2009-0-63394-8

Jiang X, Li T, Wang B (2004) Structures and mechanisms of the northward propagating boreal summer intraseasonal oscillation. J Clim 17:1022-1039. https://doi.org/10.1175/1520-0442(2004)017<1022:SAMOTN>2.0.CO;2

Kang IS, Kim D, Kug JS (2010) Mechanism for northward propagation of boreal summer intraseasonal oscillation: convective momentum transport. Geophys Res Lett 37:L24804. doi:10.1029/2010GL045072

Kummerow C et al (2000) The status of the tropical rainfall measuring mission (TRMM) after two years in orbit. J Appl Meteorol 39(12):1965-1982. https://doi.org/10.1175/1520-0450(2001)040<1965:TSOTTR>2.0.CO;2

Li B, Zhou L, Wang C, Gao C, Qin J, Meng Z (2020) Modulation of Tropical Cyclone Genesis in the Bay of Bengal by the Central Indian Ocean Mode. J Geophys Res Atmos, 125. https://doi.org/10.1029/2020JD032641

Li B, Zhou L, Qin J, Murtugudde R (2021) The Role of Vorticity Tilting in NorthwardPropagating Monsoon Intraseasonal Oscillation. Geophys Res Lett https://doi.org/10.1029/2021GL093304

Madden RA, Julian PR (1971) Detection of a 40-50 day oscillation in the zonal wind in the tropical Pacific. J Atmos Sci 28:702-708. http://dx.doi.org/10.1175/15200469(1971)028<0702:DOADOI $>2.0 . C O ; 2$

Madden RA, Julian PR (1972) Description of global-scale circulation cells in the tropics with a 40-50 day period. J Atmos Sci 29:31383158. https://doi.org/10.1175/1520-0469(1972)029<1109:DOGSCC >2.0.CO;2

Meehl GA, Arblaster JM, Caron JM, Annamalai H, Jochum M, Chakraborty A, Murtugudde R (2012) Monsoon regimes and processes in CCSM4. Part I: the Asian-Australian monsoon. J Clim 25(8):2583-2608. doi:10.1175/JCLI-D-1100184.1 
Murtugudde R, McCreary JP, Busalacchi AJ (2000) Oceanic processes associated with anomalous events in the Indian Ocean with relevance to 1997-1998. J Geophys Res Ocean 105(C2):3295-3306. doi:10.1029/1999JC900294

Pottapinjara V, Girishkumar MS, Ravichandran M, Murtugudde R (2014) Influence of the Atlantic zonal mode on monsoon depressions in the Bay of Bengal during boreal summer. J Geophys Res Atmos 119(11):6456-6469. https://doi.org/10.1002/2014JD021494

Qin J, Zhou L, Li B, Murtugudde R (2020) Simulation of Central Indian Ocean Mode in S2S Models. J Geophys Res Atmos 125(21):e2020JD033550. https://doi.org/10.1029/2020JD033550

Reynolds RW, Smith TM, Liu C, Chelton DB, Casey KS, Schlax MG (2007) Daily high-resolution-blended analyses for sea surface temperature. J Clim 20(22):5473-5496. https://doi.org/10.1175/2007JCLI1824.1

Sabeerali CT, Dandi AR, Dhakate A, Salunke K, Mahapatra S, Rao AS (2013) Simulation of boreal summer intraseasonal oscillations in the latest CMIP5 coupled GCMs. J Geophys Res Atmos 118:4401-4420. doi:10.1002/jgrd.50403

Shukla RP (2014) The dominant intraseasonal mode of intraseasonal South Asian summer monsoon. J Geophys Res 119:635-651. https://doi.org/10.1002/2013JD020335

Vallis GK (2017) Atmospheric and oceanic fluid dynamics. Cambridge University Press. https://doi.org/10.1017/9781107588417

Vitart F (2017) Madden-Julian Oscillation prediction and teleconnections in the S2S database. Q J R Meteorol Soc 143:2210-2220. https://doi.org/10.1002/qj.3079

Waliser D, Jin K, Kang IS, Stern WF et al (2003) AGCM simulations of intraseasonal variability associated with the Asian summer monsoon. Clim Dyn 21:423-446. https://xs.scihub.ltd/https://doi.org/10.1007/s00382-003-0337-1

Waliser DE (2006) Intraseasonal variability. In The Asian Monsoon (pp. 203-257). Springer, Berlin, Heidelberg. https://xs.scihub.ltd/https://doi.org/10.1007/3-54037722-0_5 
Wang B et al (2015) Rethinking Indian monsoon rainfall prediction in the context of $\begin{array}{llll}\text { recent global warming. } & \text { 6:7154. }\end{array}$ https://xs.scihub.ltd/https://doi.org/10.1038/ncomms8154

Wang J, Kim H, Kim D, Henderson S, Stan C, Maloney E (2020) MJO teleconnections over the PNA region in climate models. Part I: Performance- and process-based skill metrics. J Clim 33:1051-1067. https://doi.org/10.1175/JCLI-D-19-0253.1

Xi J, Zhou L, Murtugudde R, Jiang L (2015) Impacts of intraseasonal sst anomalies on precipitation during Indian summer monsoon. J Clim 28:4561-4575. https://doi.org/10.1175/JCLI-D-14-00096.1

Yasunari T (1981) Structure of an Indian summer monsoon system with around 40-day period. J Meteorol Soc Jpn 59:336-354. https://doi.org/10.2151/jmsj1965.59.3_336

Zhang C (2005) Madden-Julian Oscillation. Rev Geophys 43:RG2003. https://doi.org/10.1029/2004RG000158

Zhou L, Sobel AH, Murtugudde R (2012) Kinetic energy budget for the Madden-Julian oscillation in a multiscale framework. J Clim 25:5386-5403. https://doi.org/10.1175/JCLI-D-11-00339.1

Zhou L, Murtugudde R (2014) Impact of northward-propagating intraseasonal variability on the onset of indian summer monsoon. J Clim 27:126-139. https://doi.org/10.1175/JCLI-D-13-00214.1

Zhou L, Murtugudde R, Chen D, Tang Y (2017a) A Central Indian Ocean Mode and Heavy Precipitation during the Indian Summer Monsoon. J Clim 30:2055-2067. https://doi.org/10.1175/JCLI-D-16-0347.1

Zhou L, Murtugudde R, Chen D, Tang Y (2017b) Seasonal and interannual variabilities of the central Indian Ocean mode. J Clim 30:6505-6520. https://doi.org/10.1175/JCLI-D-16-0616.1

Zhou L, Murtugudde R, Neale RB, Jochum M (2018) Simulation of the Central Indian Ocean mode in CESM: Implications for the Indian summer monsoon system. $\mathrm{J}$ Geophys Res Atmos 123(1):58-72. https://doi.org/10.1002/2017JD027171 
518 Table 1. The selected 18 CMIP6 models used in our study with names, institutions and

519 horizontal grid resolution of the atmospheric and ocean variables.

\begin{tabular}{|c|c|c|c|c|}
\hline \multirow[t]{2}{*}{ No. } & \multirow[t]{2}{*}{ Model } & \multirow[t]{2}{*}{ Institution name } & \multicolumn{2}{|c|}{$\begin{array}{l}\text { Average grid resolution } \\
\text { (longitude } \mathrm{x} \text { latitude) }\end{array}$} \\
\hline & & & Atmosphere & Ocean \\
\hline 1 & ACCESS-CM2 & \multirow{2}{*}{$\begin{array}{l}\text { Commonwealth Scientific and Industrial } \\
\text { Research Organisation (CSIRO), } \\
\text { Australia }\end{array}$} & $1.87^{\circ} \times 1.25^{\circ}$ & $1.0^{\circ} \times 1.0^{\circ}$ \\
\hline 2 & $\begin{array}{l}\text { ACCESS- } \\
\text { ESM1-5 }\end{array}$ & & $1.87^{\circ} \times 1.25^{\circ}$ & $1.0^{\circ} \times 1.0^{\circ}$ \\
\hline 3 & CanESM5 & $\begin{array}{l}\text { Canadian Centre for Climate Modelling } \\
\text { and Analysis, Environment and Climate } \\
\text { Change Canada, BC, Canada }\end{array}$ & $2.8^{\circ} \times 2.8^{\circ}$ & $1.0^{\circ} \times 0.62^{\circ}$ \\
\hline 4 & CESM2 & \multirow{3}{*}{$\begin{array}{l}\text { National Center for Atmospheric } \\
\text { Research, Boulder, CO, USA }\end{array}$} & $0.9^{\circ} \times 1.25^{\circ}$ & $0.9^{\circ} \times 1.25^{\circ}$ \\
\hline 5 & CESM2-FV2 & & $1.9^{\circ} \times 2.5^{\circ}$ & $1.9^{\circ} \times 2.5^{\circ}$ \\
\hline 6 & $\begin{array}{l}\text { CESM2- } \\
\text { WACCM-FV2 }\end{array}$ & & $1.9^{\circ} \times 2.5^{\circ}$ & $1.9^{\circ} \times 2.5^{\circ}$ \\
\hline 7 & EC-Earth3-Veg & $\begin{array}{l}\text { Consortium of various institutions from } \\
\text { Spain, Italy, Denmark, Finland, Germany, } \\
\text { Ireland, Portugal, Netherlands, Norway, } \\
\text { the United Kingdom, Belgium, and } \\
\text { Sweden }\end{array}$ & $0.7^{\circ} \times 0.7^{\circ}$ & $1.0^{\circ} \times 0.62^{\circ}$ \\
\hline 8 & GFDL-CM4 & $\begin{array}{l}\text { Geophysical Fluid Dynamics Laboratory, } \\
\text { NOAA, Princeton, NJ, USA }\end{array}$ & $1.0^{\circ} \times 1.0^{\circ}$ & $0.25^{\circ} \times 0.16^{\circ}$ \\
\hline 9 & $\begin{array}{l}\text { IPSL-CM6A- } \\
\text { LR }\end{array}$ & $\begin{array}{l}\text { Institute Pierre Simon Laplace, Paris, } \\
\text { France }\end{array}$ & $2.5^{\circ} \times 1.25^{\circ}$ & $1.0^{\circ} \times 0.54^{\circ}$ \\
\hline 10 & MIROC6 & $\begin{array}{l}\text { Japan Agency for Marine-Earth Science } \\
\text { and Technology, Atmosphere and Ocean } \\
\text { Research Institute, National Institute for } \\
\text { Environmental Studies, and RIKEN } \\
\text { Center for Computational Science, Japan }\end{array}$ & $1.4^{\circ} \times 1.4^{\circ}$ & $1.0^{\circ} \times 0.70^{\circ}$ \\
\hline 11 & $\begin{array}{l}\text { MPI-ESM-1-2- } \\
\text { HAM }\end{array}$ & \multirow{3}{*}{$\begin{array}{l}\text { Max Planck Institute fur Meteorologie, } \\
\text { Forschungszentrum Julich, University of } \\
\text { Oxford, Finnish Meteorological Institute, } \\
\text { Leibniz Institute for Tropospheric } \\
\text { Research, ETH Zurich }\end{array}$} & $1.87^{\circ} \times 1.87^{\circ}$ & $1.52^{\circ} \times 0.82^{\circ}$ \\
\hline 12 & $\begin{array}{l}\text { MPI-ESM1-2- } \\
\text { HR }\end{array}$ & & $0.94^{\circ} \times 0.94^{\circ}$ & $0.45^{\circ} \times 0.45^{\circ}$ \\
\hline 13 & $\begin{array}{l}\text { MPI-ESM1-2- } \\
\text { LR }\end{array}$ & & $1.87^{\circ} \times 1.87^{\circ}$ & $1.4^{\circ} \times 0.82^{\circ}$ \\
\hline 14 & MRI-ESM2-0 & $\begin{array}{lll}\text { Meteorological } & \text { Research } & \text { Institute, } \\
\text { Tsukuba, Japan } & & \\
\end{array}$ & $1.1^{\circ} \times 1.1^{\circ}$ & $1.0^{\circ} \times 0.5^{\circ}$ \\
\hline 15 & NESM3 & $\begin{array}{l}\text { Nanjing University of Information } \\
\text { Science and Technology, Nanjing, China }\end{array}$ & $1.87^{\circ} \times 1.87^{\circ}$ & $1.0^{\circ} \times 0.62^{\circ}$ \\
\hline 16 & NorESM2-LM & \multirow{2}{*}{ Norwegian Climate Centre, Norway } & $0.467^{\circ} \times 1.0^{\circ}$ & $1.875^{\circ} \times 2.5^{\circ}$ \\
\hline 17 & NorESM2-MM & & $0.467^{\circ} \times 1.0^{\circ}$ & $0.94^{\circ} \times 1.25^{\circ}$ \\
\hline 18 & $\begin{array}{l}\text { SAM0- } \\
\text { UNICON }\end{array}$ & $\begin{array}{l}\text { Seoul National University, Seoul, } \\
\text { Republic of Korea }\end{array}$ & $1.25^{\circ} \times 0.94^{\circ}$ & $1.1^{\circ} \times 0.47^{\circ}$ \\
\hline
\end{tabular}


520 Table 2. Classifications of well and poorly simulated groups in CMIP6 models.

\begin{tabular}{l|l|l|l}
\hline No. & The poorly simulated group & No. & The well simulated group \\
\hline 1 & ACCESS-CM2 & 5 & CESM2-FV2 \\
\hline 2 & ACCESS-ESM1-5 & 6 & CESM2-WACCM-FV2 \\
\hline 3 & CanESM5 & 10 & MIROC6 \\
\hline 9 & CESM2 & 18 & SAM0-UNICON \\
\hline
\end{tabular}

521

522

523 
Table 3. The numbers of CIO mode events in 18 CMIP6 air-sea coupled models.

\begin{tabular}{l|l|l|l|l|l}
\hline No. & Model & $\begin{array}{l}\text { Numbers } \\
\text { of events }\end{array}$ & No. & Model & $\begin{array}{l}\text { Numbers } \\
\text { of events }\end{array}$ \\
\hline 1 & ACCESS-CM2 & 57 & 10 & MIROC6 & 56 \\
\hline 2 & ACCESS-ESM1-5 & 67 & 11 & MPI-ESM-1-2-HAM & 58 \\
\hline 3 & CanESM5 & 59 & 12 & MPI-ESM1-2-HR & 55 \\
\hline 5 & CESM2 & 60 & 13 & MPI-ESM1-2-LR & 56 \\
\hline 6 & $\begin{array}{l}\text { CESM2-WACCM- } \\
\text { FV2 }\end{array}$ & 64 & 15 & NESM3 & 60 \\
\hline 7 & EC-Earth3-Veg & 56 & 16 & NorESM2-LM & 61 \\
\hline 8 & GFDL-CM4 & 68 & 17 & NorESM2-MM & 57 \\
\hline
\end{tabular}



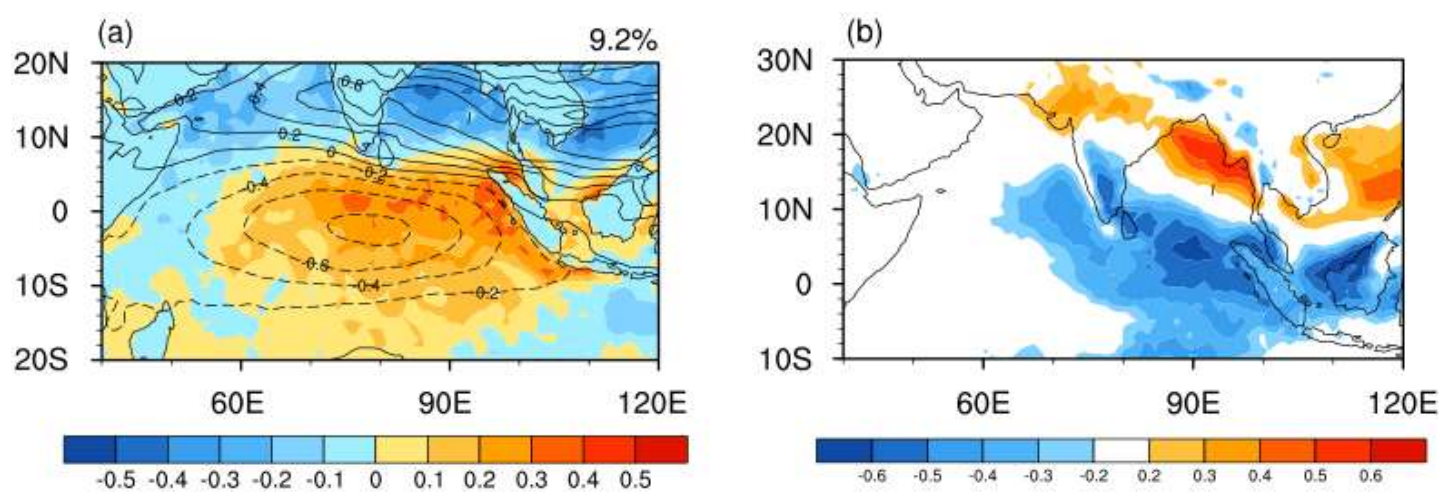

(c)
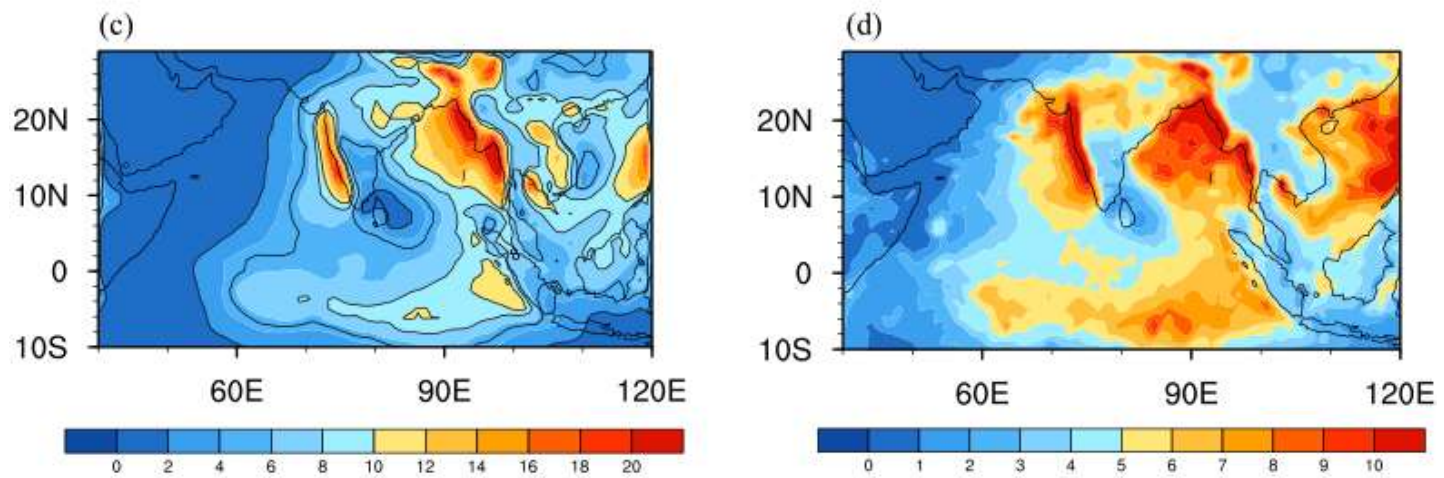

Figure 1 (a) The spatial structure of positive CIO mode obtained by daily OISST and

ERA5 reanalysis from 1998 to 2014. Colors denote the SST node, and solid (dashed)

contours denote westerly (easterly) winds. (b) Correlation maps of the CIO mode index

with intraseasonal precipitation during the ISM. (c) Climatological mean of total precipitation $(\mathrm{mm})$ calculated by TRMM from June to September during the period 1998-2014. (d) is the same as (c), but for standard deviation of intraseasonal precipitation $(\mathrm{mm})$. 

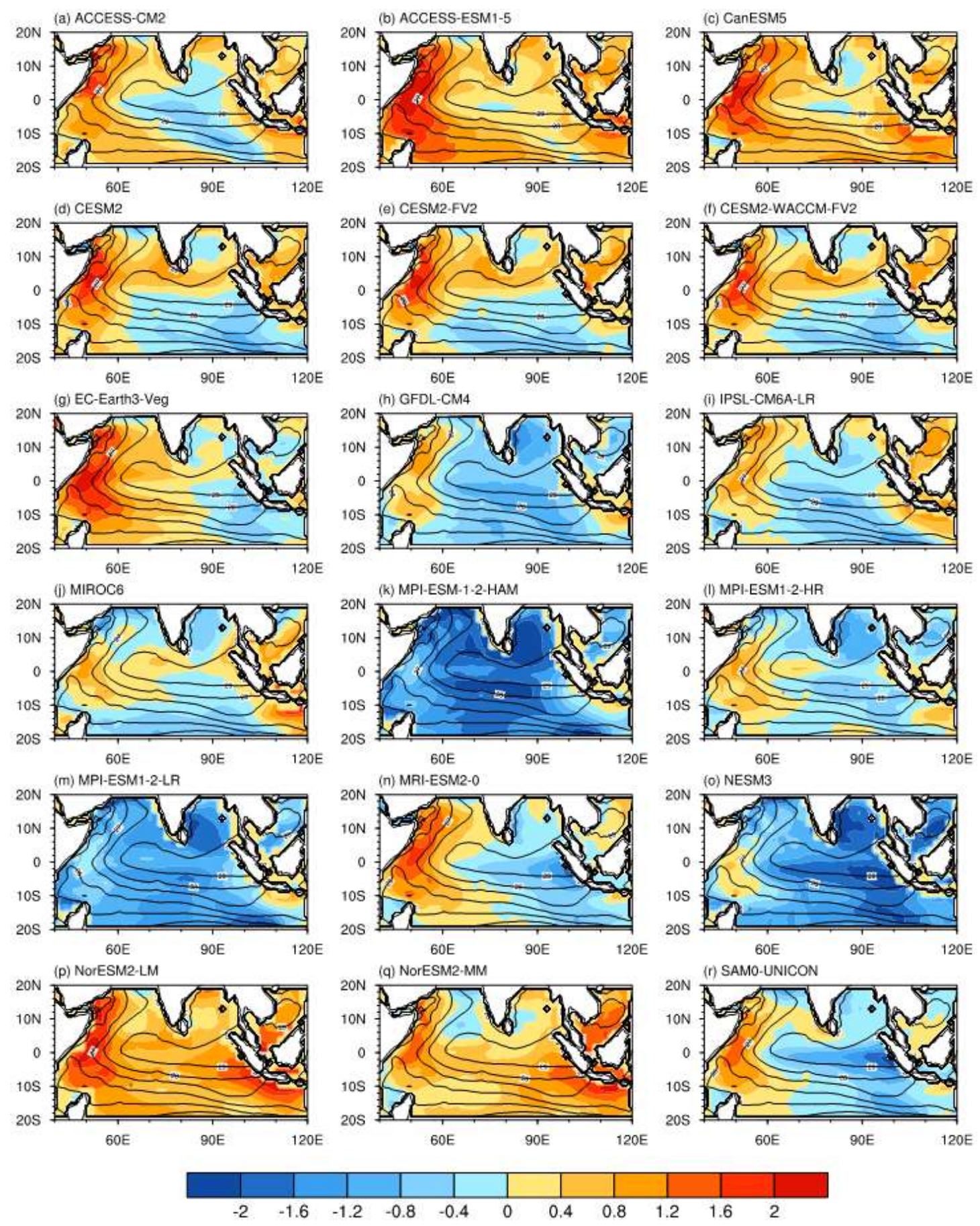

538 Figure 2 Differences of SST between observations and CMIP6 models (colors,

539 simulations minus observations) averaged from June to September. Contours denote the

540 observed SST. The unit is ${ }^{\circ} \mathrm{C}$. 

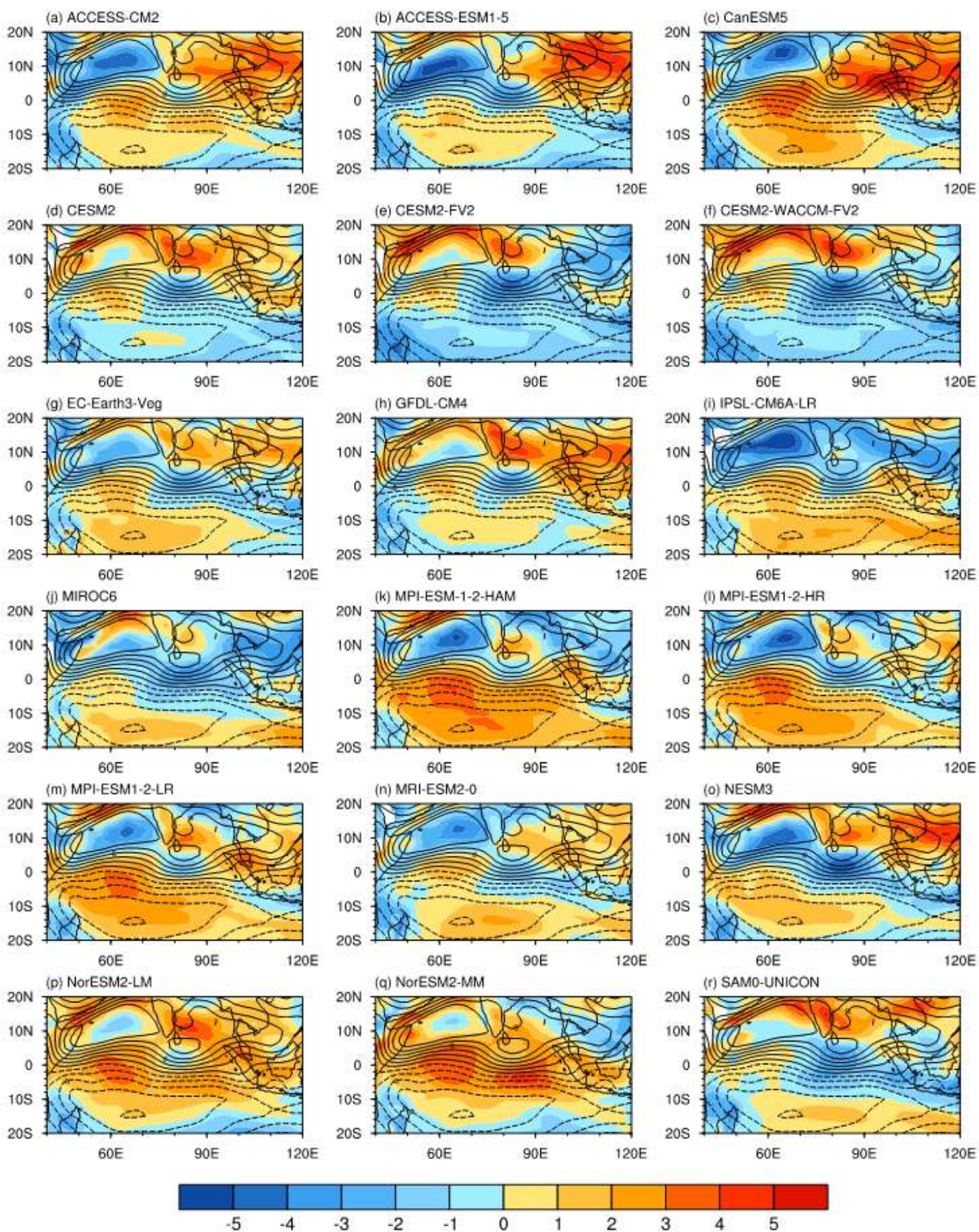

543 Figure 3 Differences of U850 between observations and CMIP6 models (colors,

544 simulations minus observations) averaged from June to September. Contours denote the

545 observed U850. The unit is $\mathrm{m} \mathrm{s}^{-1}$. 


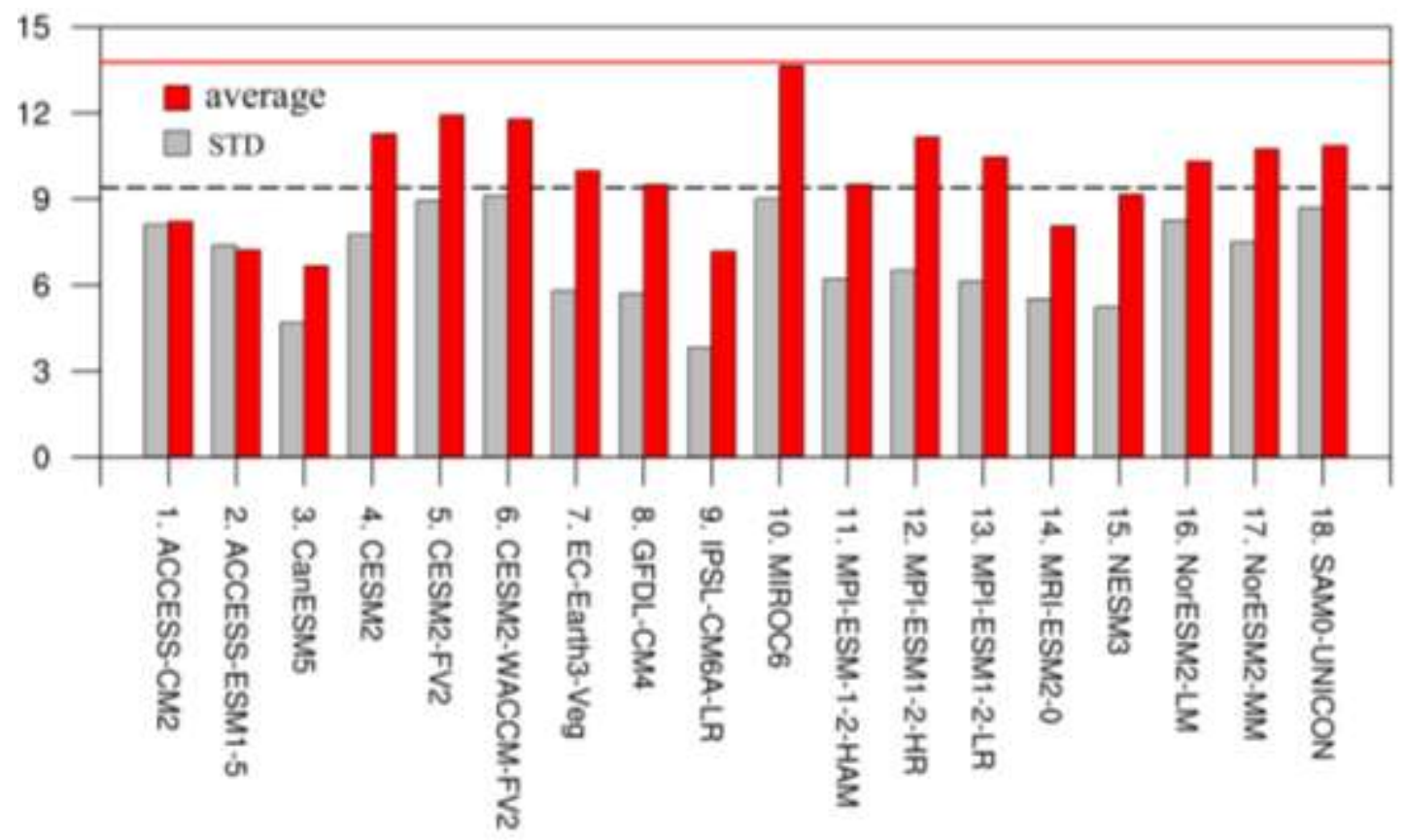

Figure 4 The total precipitation (red bars) and standard deviation of intraseasonal 550 precipitation (gray bars) averaged in the $\mathrm{BoB}\left(10^{\circ}-20^{\circ} \mathrm{N}, 80^{\circ}-100^{\circ} \mathrm{E}\right.$, where the 551 monsoonal precipitation is large) during boreal summer (June-September) in CMIP6 models. The red and gray lines represent the observations. 

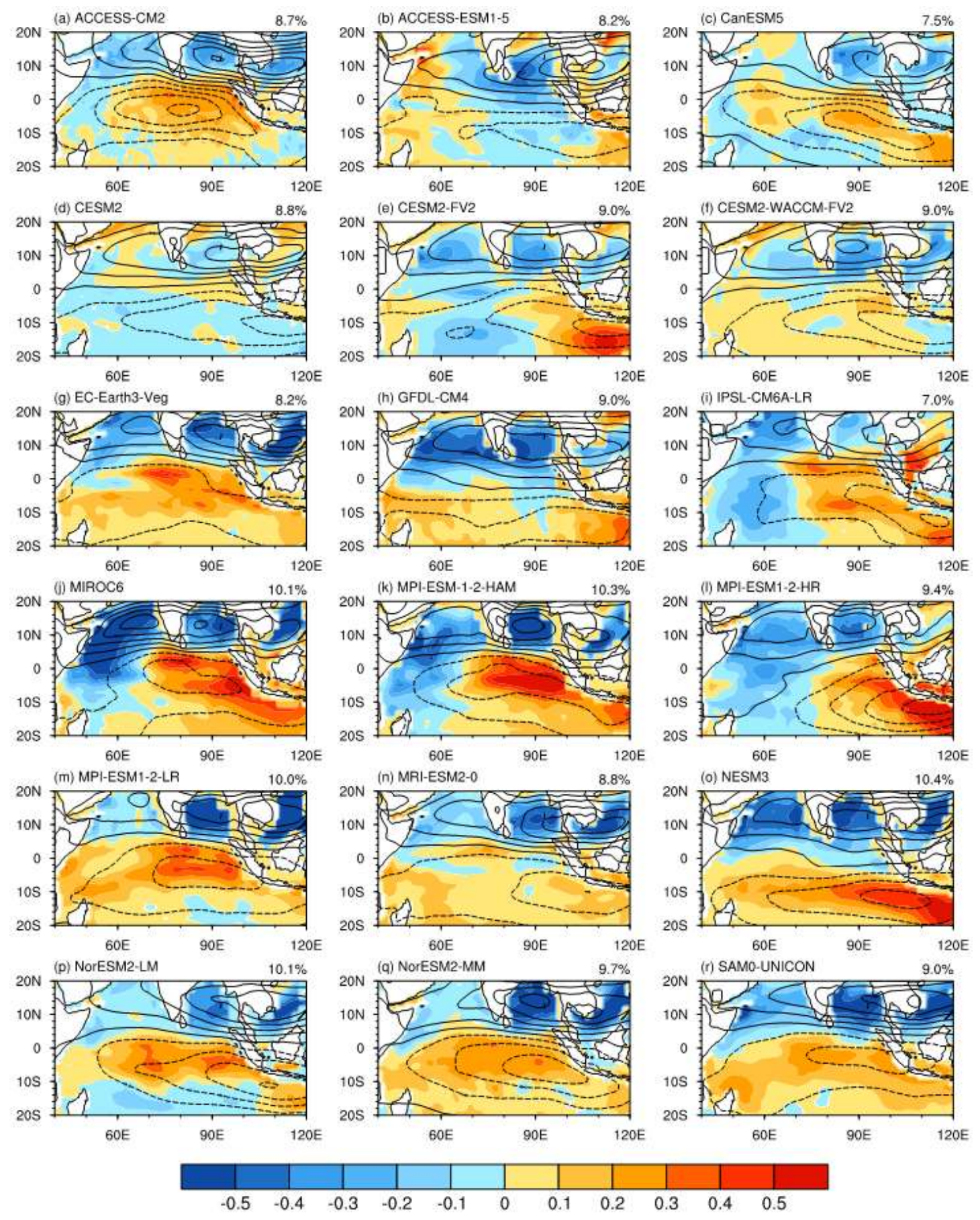

555 Figure 5 The spatial structure of simulated CIO mode obtained by CMIP6 models.

556 Colors denote the SST node, and solid (dashed) contours denote westerly (easterly)

557 winds. The explanation variance of simulated CIO mode is labelled in each model. 

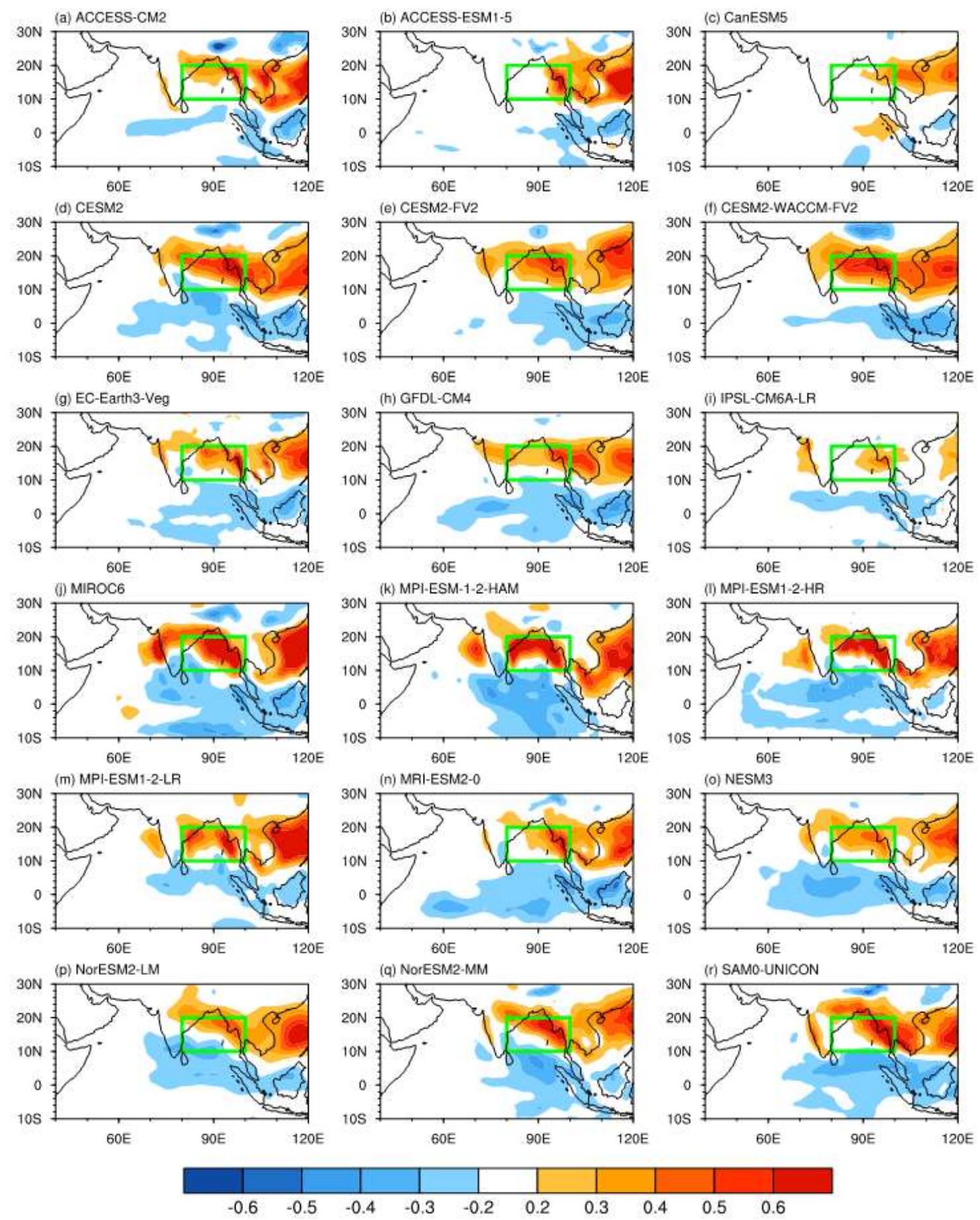

561 Figure 6 Correlation maps of the projected CIO mode index with the intraseasonal

562 precipitation over the tropical Indian Ocean during the ISM in CMIP6 models. Green

563 boxes represent $10^{\circ}-20^{\circ} \mathrm{N}, 80^{\circ}-100^{\circ} \mathrm{E}$, where the positive correlation coefficients are

564 large in observation (Fig. 1b). Only correlations significant at a 95\% confidence level

565 are shown. 


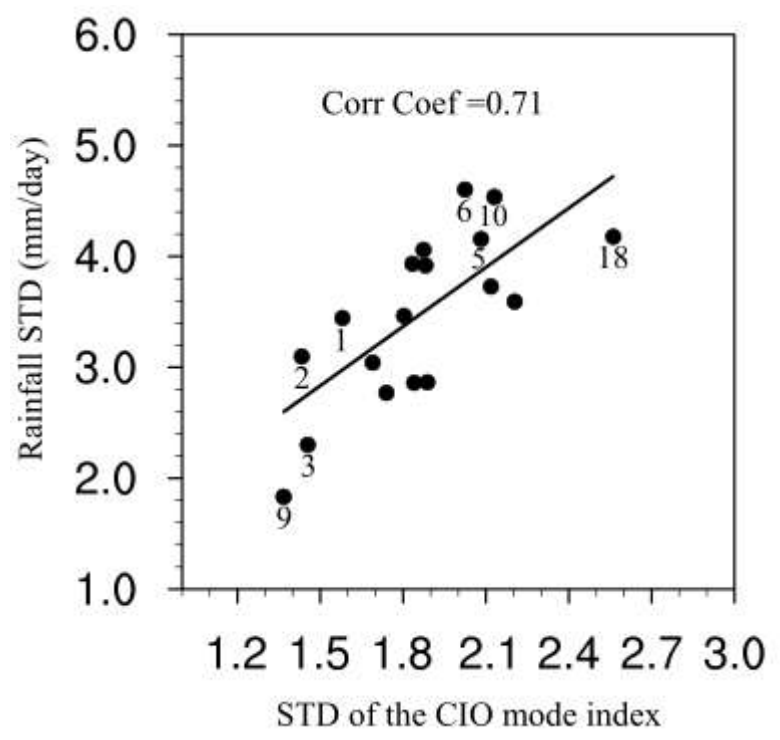

Figure 7 The scatter plot of the standard deviation of intraseasonal precipitation (y-axis, $\mathrm{mm}$ day-1) in the northern $\mathrm{BoB}$ (averaged within $10^{\circ} \mathrm{N}-20^{\circ} \mathrm{N}$ and $85^{\circ} \mathrm{E}-100^{\circ} \mathrm{E}$ ) with respect to the standard deviation of the projected CIO mode indices (x-axis) in CMIP6 models. The black line shows the linear regression of the scatter plot and the regression coefficient is statistically significant at the $99 \%$ confidence level. 

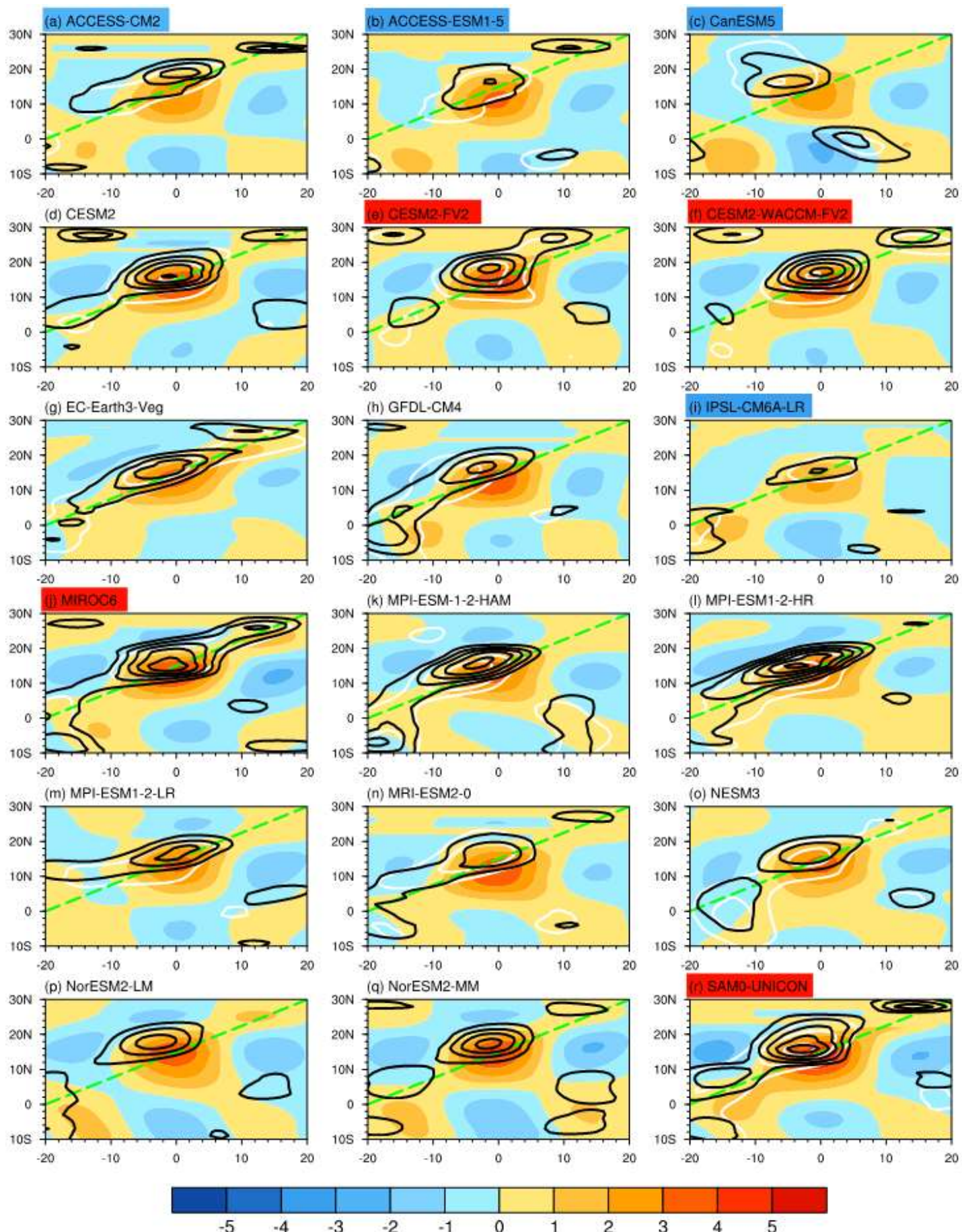

$-2$

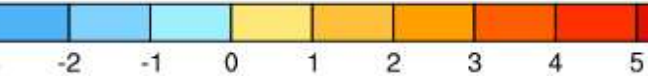

Figure 8 Composite Hovmöller diagram of intraseasonal precipitation (black solid contours; $\mathrm{mm}$ day $^{-1}$ ), intraseasonal OLR (white solid contours; $\mathrm{W} \mathrm{m}^{-2}$ ), and intraseasonal zonal wind (colors; $\mathrm{m} \mathrm{s}^{-1}$ ), averaged between $80^{\circ} \mathrm{E}$ and $90^{\circ} \mathrm{E}$, calculated with CMIP6 models. Day 0 of the $\mathrm{x}$-axis is the day when the projected CIO mode index reaches its maximum during the ISM. Negative days are before Day 0 and positive days are after Day 0 . The green dashed lines represent the reference lines. The rainfalls from

$5811 \mathrm{~mm} \mathrm{day}^{-1}$ to $10 \mathrm{~mm} \mathrm{day}^{-1}$ interval $1 \mathrm{~mm} \mathrm{day}^{-1}$ are shown. The OLRs from $-5 \mathrm{~W} \mathrm{~m}^{-2}$ 
582 to $-20 \mathrm{~W} \mathrm{~m}^{-2}$ interval $5 \mathrm{~W} \mathrm{~m}^{-2}$ are shown. The OLRs are not available in NorESM2-LM

583 and NorESM2-MM. The well (poorly) simulated group (listed in Tab.2) is shaded with 584 red (blue) colors.

585 

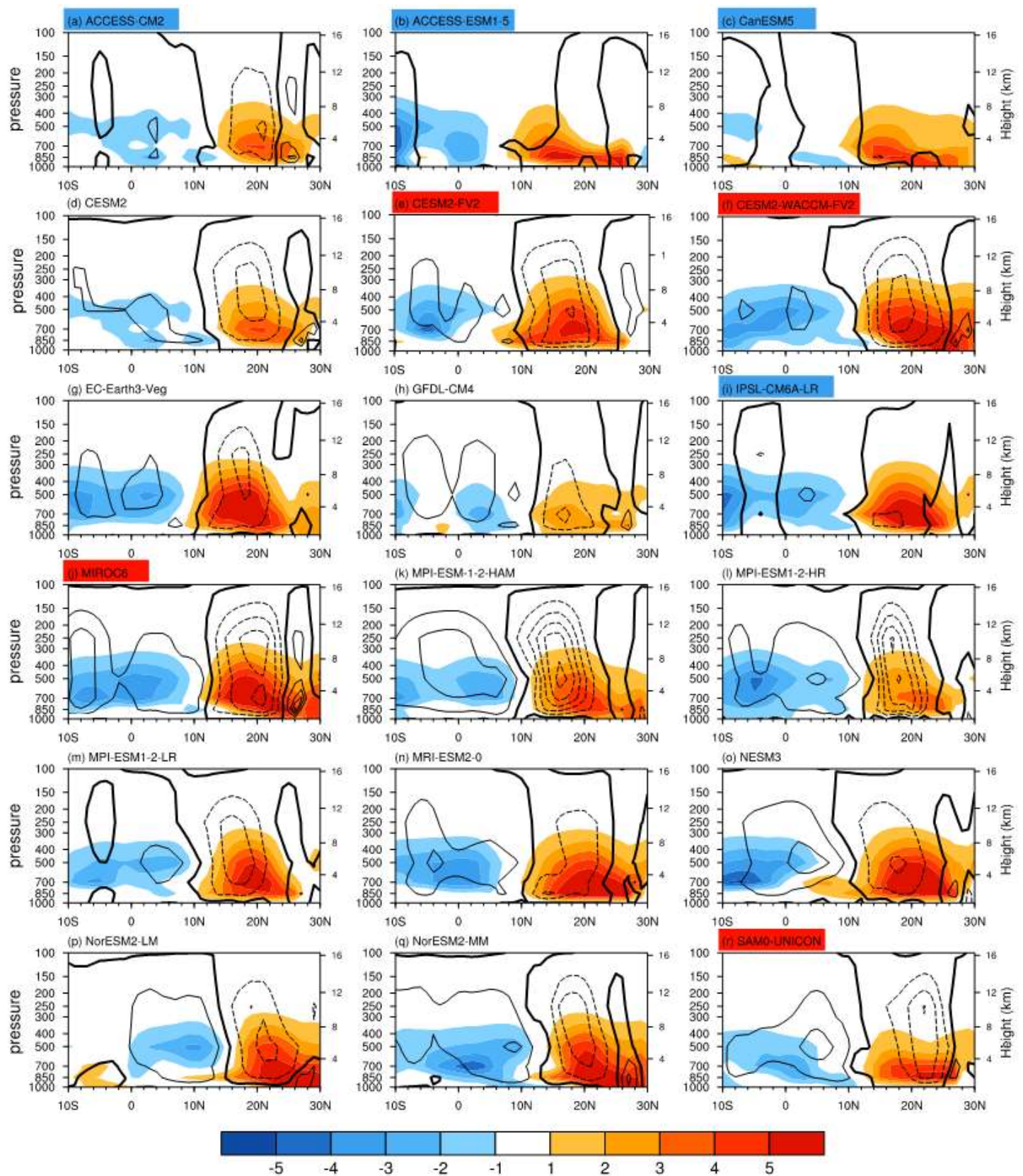

Figure 9 Composites of intraseasonal specific humidity (colors, $\mathrm{g} \mathrm{kg}^{-1}$ ) and omega (contours, $\mathrm{Pa} \mathrm{s}^{-1}$ ) between $80^{\circ} \mathrm{E}$ and $90^{\circ} \mathrm{E}$ for CMIP6 models when the projected CIO mode index reaches its maximum during the ISM. Only intraseasonal specific humidity significant at 95\% confidence level are shown. Solid contours for negative omega

591 (upstream) and dashed contours for positive omega (downstream). The omega from -5

$592 \mathrm{~Pa} \mathrm{~s}^{-1}$ to $-2 \mathrm{~Pa} \mathrm{~s}^{-1}$ interval $1 \mathrm{~Pa} \mathrm{~s}^{-1}$ are shown. Lines with a value of zero are bolded. The

593 well (poorly) simulated group (listed in Tab.2) is shaded with red (blue) colors. 
(a) intraseasonal kinetic energy

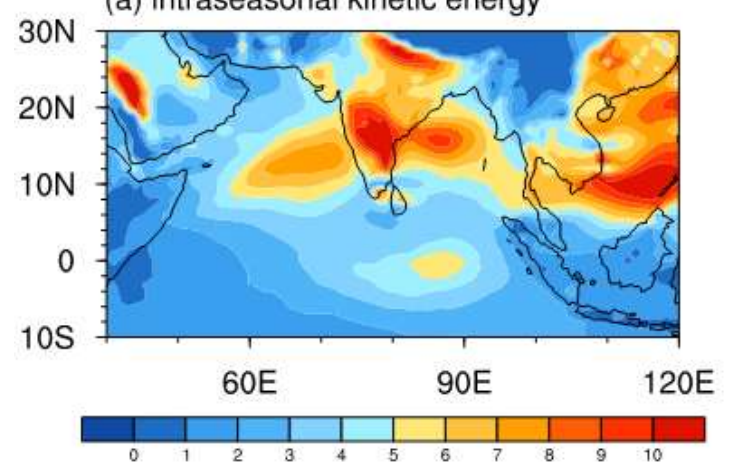

(c)

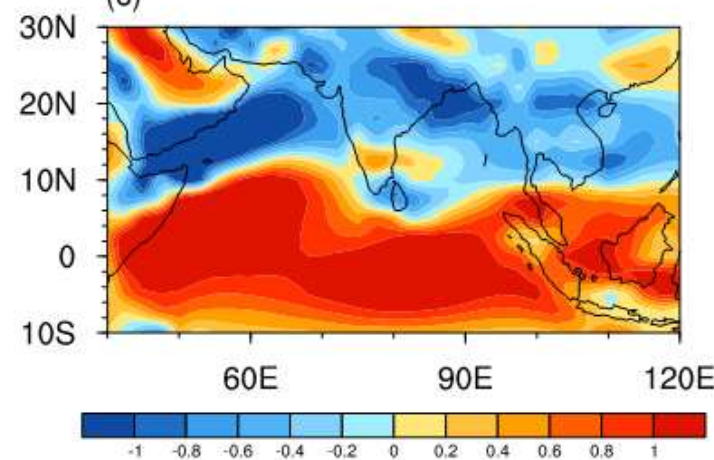

(b)

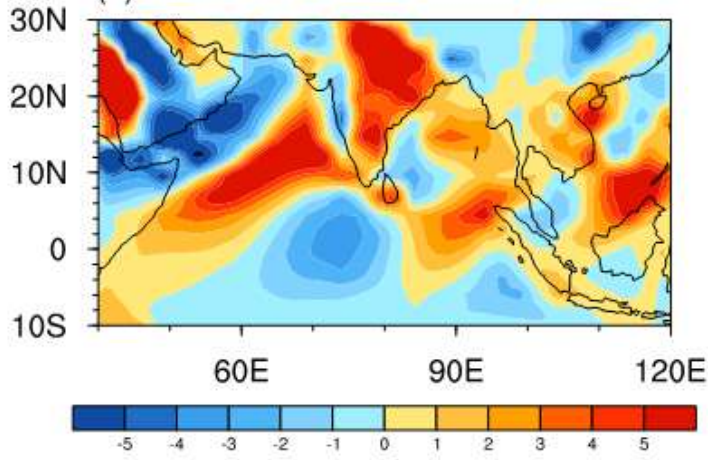

(d)

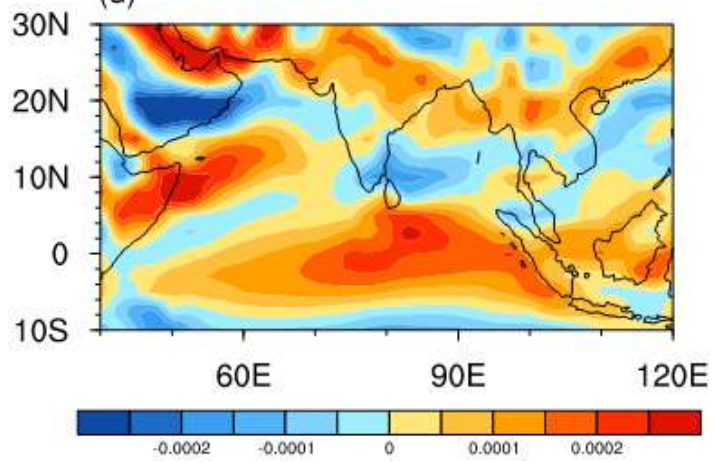

595

Figure 10 (a) Intraseasonal kinetic energy $\left(\mathrm{J} \mathrm{kg}^{-1}\right)$, (b) $\left[K E^{\prime} \times \overline{K E}\right]\left(\mathrm{J} \mathrm{day}^{-1} \mathrm{~kg}^{-1}\right),(\mathrm{c})$ $\partial \overline{\mathrm{u}} / \partial \mathrm{y}$ and (d) $\beta-\frac{\partial^{2} \bar{u}}{\partial y^{2}}$ at $850 \mathrm{hPa}$ averaged during boreal summer (from June to September) in ERA5. 

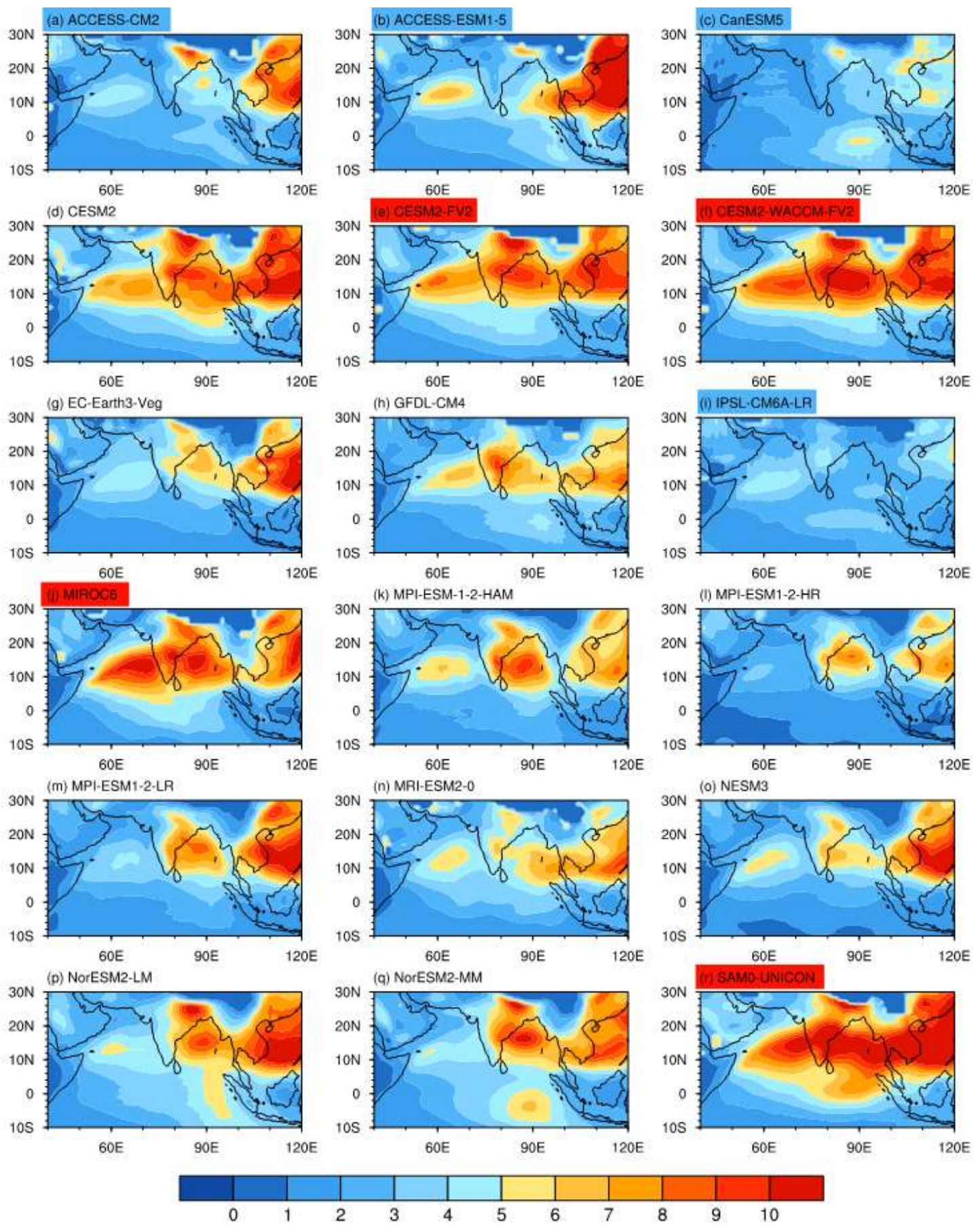

602 Figure 11 is the same as Fig. 10a, but for CMIP6 models. The unit is $\mathrm{J} \mathrm{kg}^{-1}$. The well

603 (poorly) simulated group (listed in Tab.2) is shaded with red (blue) colors. 

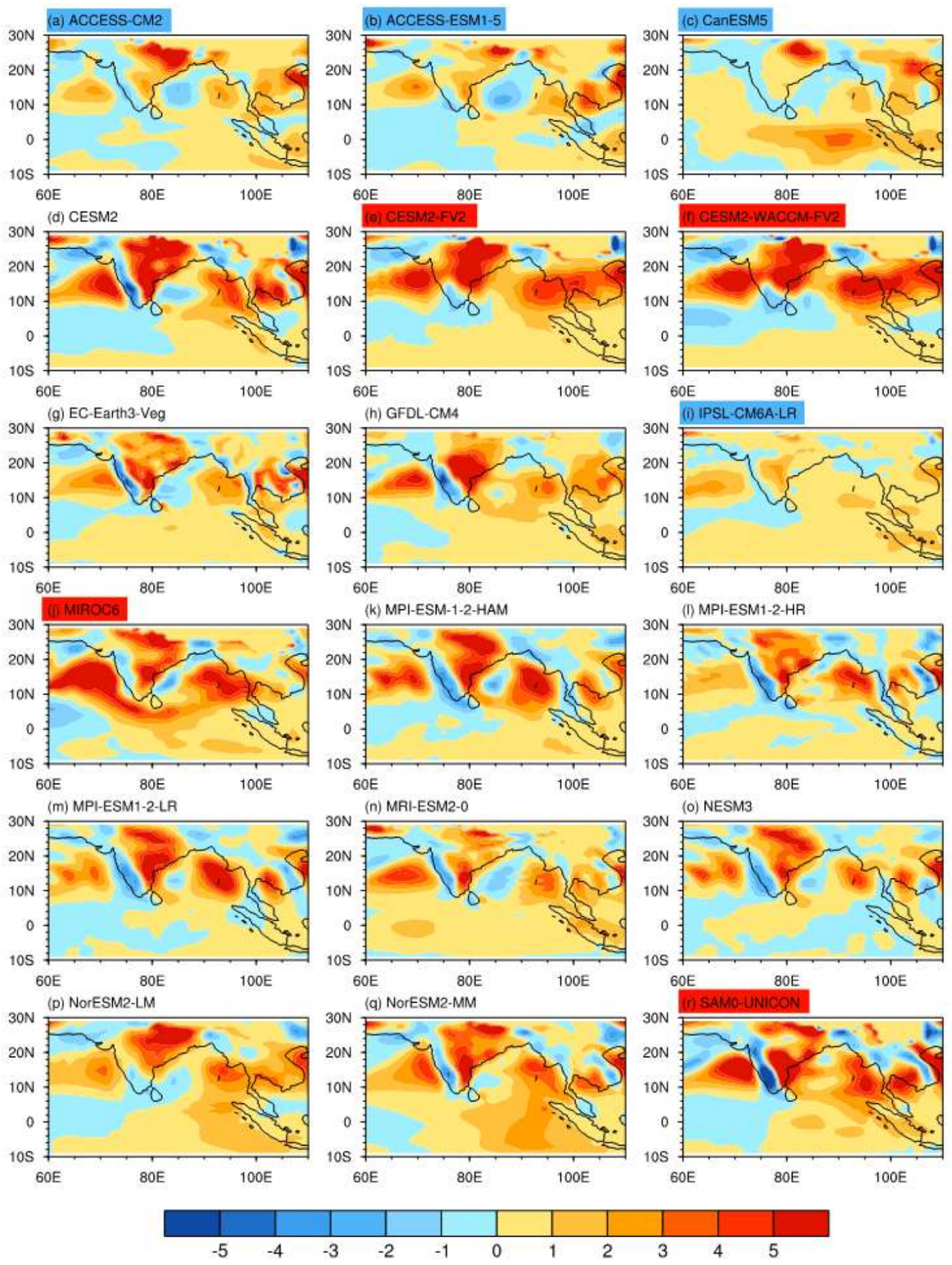

606 Figure 12 is the same as Fig. 10b, but for CMIP6 models. The unit is $\mathrm{J} \mathrm{day}^{-1} \mathrm{~kg}^{-1}$. The well (poorly) simulated group (listed in Tab.2) is shaded with red (blue) colors. 

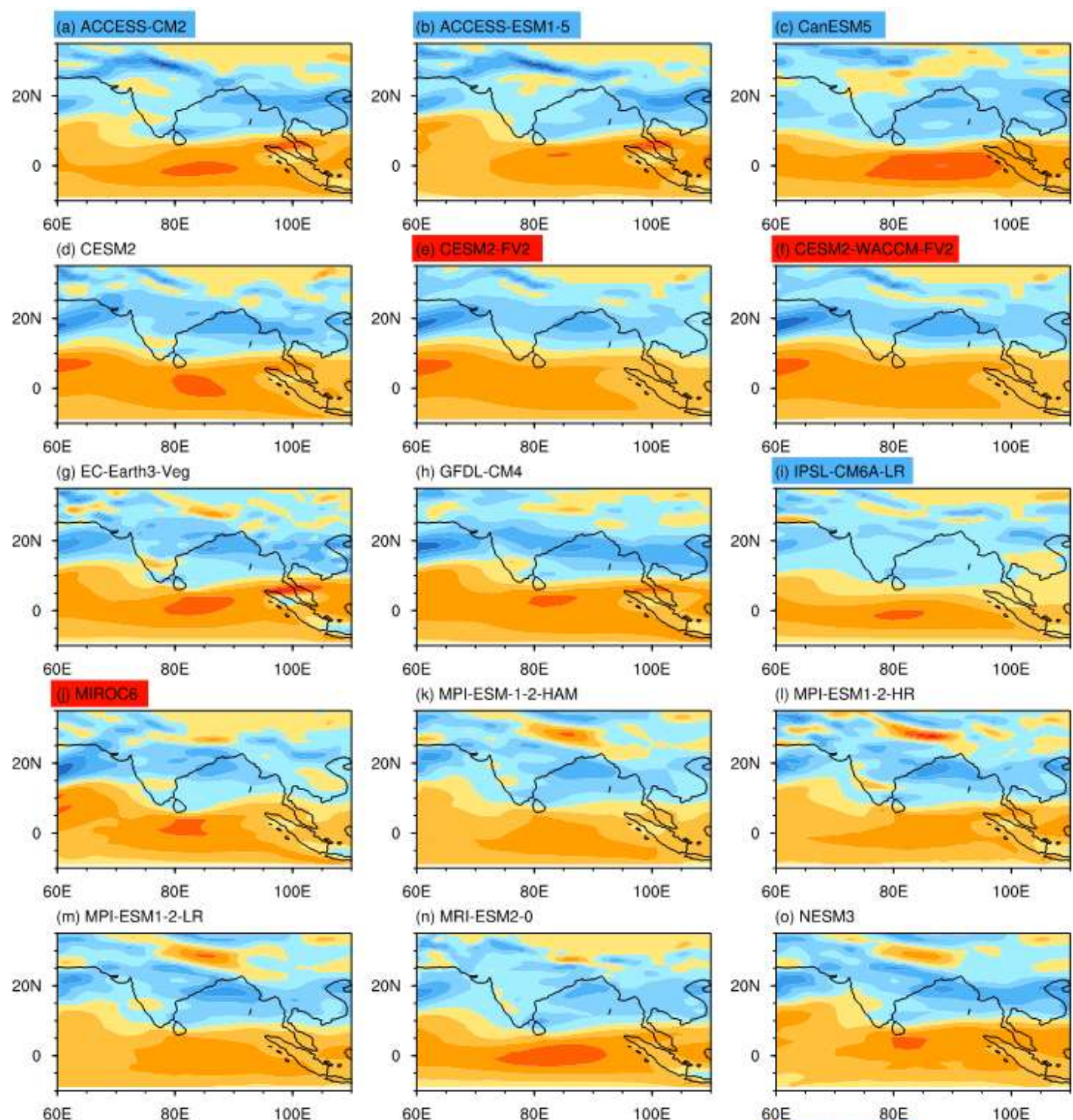

$60 \mathrm{E}$
(n) MRI-ESM2-0

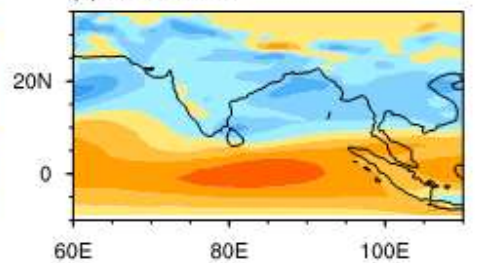

(o) NESM3
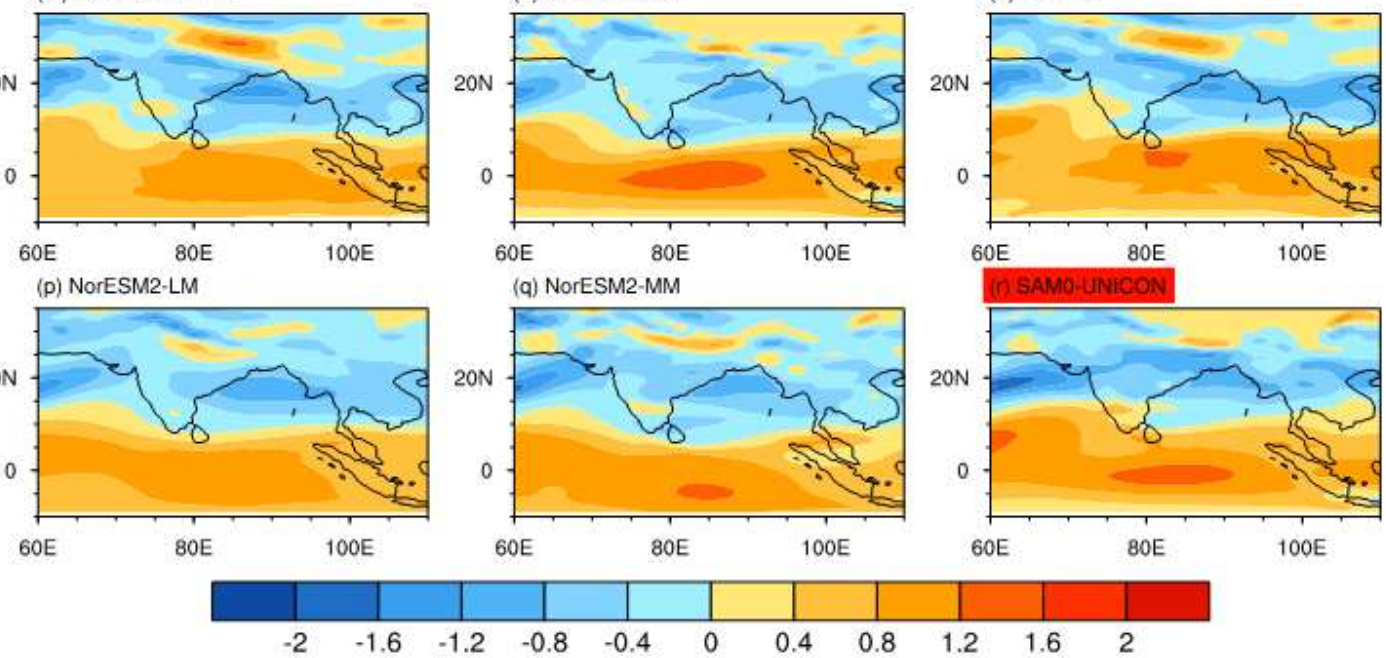

$\begin{array}{lll}60 \mathrm{E} & 80 \mathrm{E} & 100 \mathrm{E}\end{array}$

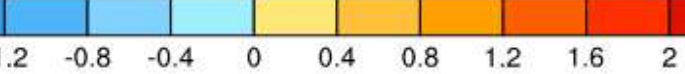

613 Figure 13 is the same as Fig. 10c, but for CMIP6 models. The well (poorly) simulated

614 group (listed in Tab.2) is shaded with red (blue) colors. 

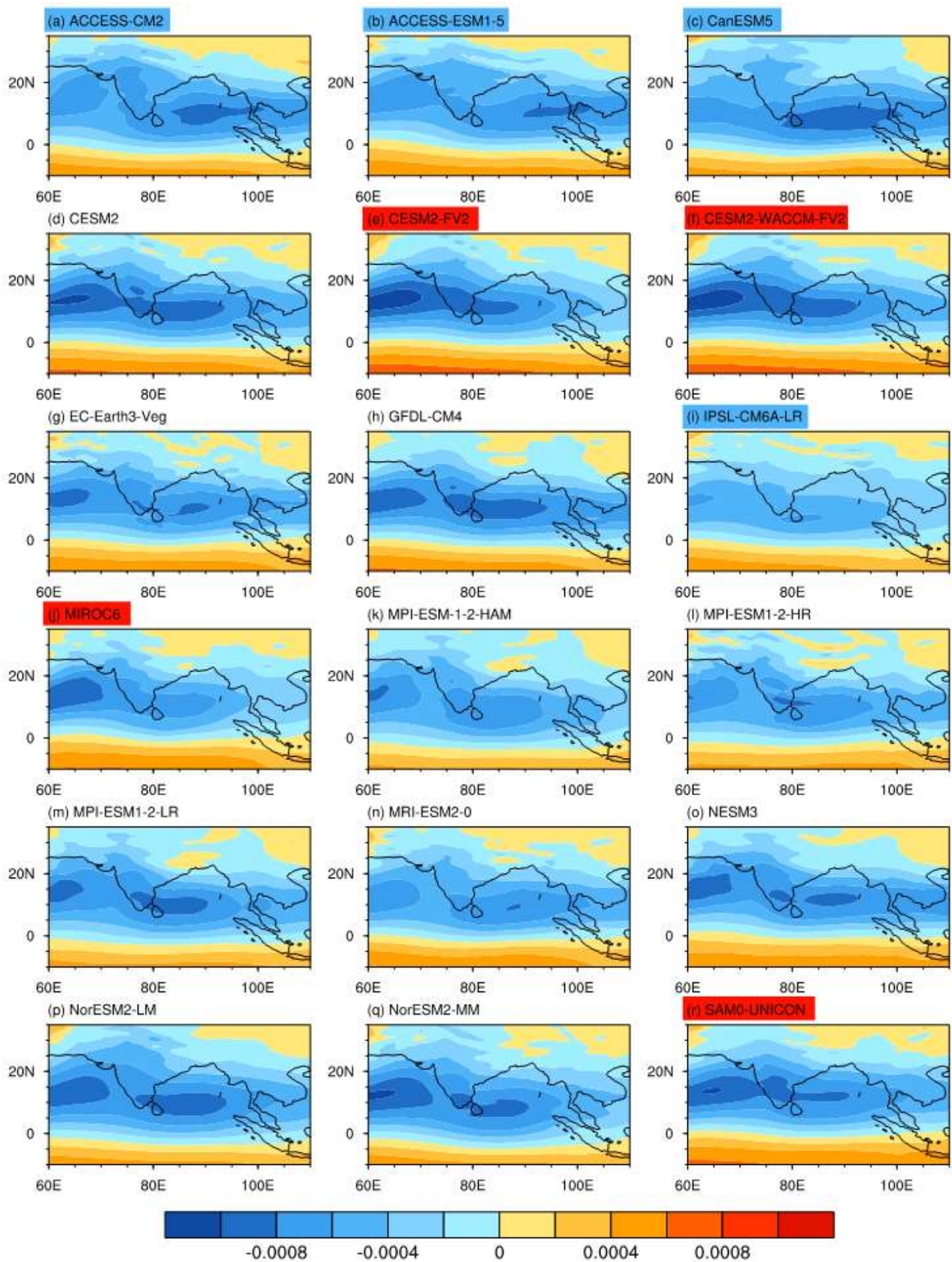

617 Figure 14 is the same as Fig. 10d, but for CMIP6 models. The well (poorly) simulated 618 group (listed in Tab.2) is shaded with red (blue) colors. 